\title{
Mechanistic Multi-Tissue Modeling of Glucocorticoid-Induced Leucine Zipper Regulation: Integrating Circadian Gene Expression with Receptor-Mediated Corticosteroid Pharmacodynamics
}

\author{
Vivaswath S. Ayyar, Debra C. DuBois, Richard R. Almon, and William J. Jusko \\ Department of Pharmaceutical Sciences, School of Pharmacy and Pharmaceutical Sciences (V.S.A., D.C.D., R.R.A., W.J.J.), and \\ Department of Biological Sciences (D.C.D., R.R.A.), State University of New York at Buffalo, Buffalo, New York
}

Received May 19, 2017; accepted July 11, 2017

\begin{abstract}
The glucocorticoid-induced leucine zipper (GILZ) is an important mediator of anti-inflammatory corticosteroid action. The pharmacokinetic/pharmacodynamic/pharmacogenomic effects of acute and chronic methylprednisolone (MPL) dosing on the tissuespecific dynamics of GILZ expression were examined in rats. A mechanism-based model was developed to investigate and integrate the role of MPL and circadian rhythms on the transcriptional enhancement of GILZ in multiple tissues. Animals received a single $50-\mathrm{mg} / \mathrm{kg}$ intramuscular bolus or a 7 -day $0.3-\mathrm{mg} / \mathrm{kg} / \mathrm{h}$ subcutaneous infusion of MPL and were euthanized at several time points. An additional group of rats were euthanized at several times and served as 24-hour light/dark (circadian) controls. Plasma MPL and corticosterone concentrations were measured by high-performance liquid chromatography. The expression of GILZ and glucocorticoid receptor (GR) mRNA was quantified in tissues using quantitative real-time reverse-transcription polymerase chain
\end{abstract}

reaction. The pharmacokinetics of MPL were described using a two-compartment model. Mild-to-robust circadian oscillations in GR and GILZ mRNA expression were characterized in muscle, lung, and adipose tissues and modeled using Fourier harmonic functions. Acute MPL dosing caused significant down-regulation (40\%-80\%) in GR mRNA and enhancement of GILZ mRNA expression (500\%-1080\%) in the tissues examined. While GILZ returned to its rhythmic baseline following acute dosing, a new steady-state was observed upon enhancement by chronic dosing. The model captured the complex dynamics in all tissues for both dosing regimens. The model quantitatively integrates physiologic mechanisms, such as circadian processes and GR tolerance phenomena, which control the tissue-specific regulation of GILZ by corticosteroids. These studies characterize GILZ as a pharmacodynamic marker of corticosteroid actions in several tissues.

\section{Introduction}

Corticosteroids (CS) are potent anti-inflammatory and immunosuppressive drugs widely used in treating diseases such as rheumatoid arthritis (Kirwan, 1995), asthma (Barnes, 1998), and some lymphomas (Kofman et al., 1962). They exert both therapeutic and adverse effects in tissues upon binding the ubiquitously expressed glucocorticoid receptors (GRs). Upon binding the GR, CS can cause effects which are rapid in onset, such as cell trafficking and adrenal suppression (Yao et al., 2008). In contrast, pharmacogenomic regulation by the drug-receptor complex occurs in a delayed fashion (Jusko, 1995) due to a series of intracellular transduction steps, including gene regulation and consequent mRNA and protein synthesis. In this manner, CS dosing elicits widespread changes in gene expression in multiple tissues (Almon et al., 2005a,b, 2007b).

This work was supported by the National Institutes of Health Nationa Institute of General Medical Sciences [Grant GM24211].

https://doi.org/10.1124/jpet.117.242990.
One such gene that is highly regulated by CS is the glucocorticoid-induced leucine zipper (GILZ). GILZ has emerged as an important mediator of the anti-inflammatory actions of CS (Ayroldi and Riccardi, 2009). Its major mechanism of action involves binding to the p65 subunit of $\mathrm{NF}_{\kappa} \mathrm{B}$ (Di Marco et al., 2007), thereby repressing its translocation into the nucleus and consequent proinflammatory gene expression. Recent evidence also demonstrates its role in modulating tumor growth and cell proliferation (Ayroldi et al., 2015; Bruscoli et al., 2015). Therefore, pharmacologic enhancement of GILZ will influence CS therapy.

Many CS-regulated genes, including GILZ, have been previously examined. However, most studies were performed in vitro and, hence, are unable to provide holistic information regarding underlying systemic and tissue-specific processes. Furthermore, little is known regarding the temporal patterns of CS-regulated genes in vivo and their governing mechanisms. Development of mechanistic pharmacokinetic (PK) and pharmacodynamic (PD) models is essential for gaining quantitative understanding of the physiologic and pharmacological mechanisms underlying the time course of diverse drug responses.

ABBREVIATIONS: ADX, adrenalectomized; CS, corticosteroid; CST, corticosterone; CV, coefficient of variation; GILZ, glucocorticoid-induced leucine zipper; GR, glucocorticoid receptor; GRE, glucocorticoid-response element; IC, initial conditions; IDR, indirect response; MPL, methylprednisolone; PD, pharmacodynamic; PEPCK, phosphoenolpyruvate carboxylase; PK, pharmacokinetic; qRT-PCR, quantitative real-time reverse-transcription polymerase chain reaction; TAT, tyrosine aminotransferase. 
Such PK/PD models have been developed in our laboratory to describe the receptor/gene-mediated effects of steroids on target genes, such as tyrosine aminotransferase (TAT) (Ramakrishnan et al., 2002a), glutamine synthetase (Sun et al., 1999), and phosphoenolpyruvate carboxylase (PEPCK) (Jin et al., 2004), in adrenalectomized $(\mathrm{ADX})$ rats.

Although TAT, glutamine synthetase, and PEPCK are useful biomarkers to probe the genomic effects of CS, they share a common limitation-in vivo expression is confined to one or two tissues. The rate-limiting enzyme in tyrosine metabolism, TAT, lacks a direct clinical relevance. PEPCK, which catalyzes the rate-limiting step of gluconeogenesis, is regulated by various hormones, including CS, glucagon, and insulin, confounding the simple assessment of CS effects alone. In contrast, several features make GILZ a robust marker to investigate CS sensitivity. First, GILZ is ubiquitously expressed in multiple tissues in humans and in the rat (Cannarile et al., 2001; Ayyar et al., 2015). Second, GILZ shows exquisite sensitivity to enhancement by CS due to the presence of multiple functional glucocorticoid-response elements (GREs) in its 5 '-upstream promoter region (van der Laan et al., 2008). Finally, GILZ expression is, at least in part, directly related to the anti-inflammatory efficacy of CS.

Since adrenal release of endogenous glucocorticoid hormones occurs in a rhythmic manner, their downstream target genes in peripheral tissues may be expected to follow similar oscillations. Indeed, many steroid-regulated genes, including cholesterol-7a-hydroxylase, TAT, and GR, exhibit circadian rhythms (Van Cantfort and Gielen, 1979; Sukumaran et al., 2010). GILZ also demonstrates a circadian rhythm in vivo, which is entrained to that of plasma corticosterone (CST) in rats (Ayyar et al., 2015). Such circadian responses add timedependent complexities (Jusko, 1995), which must be accounted for while evaluating drug effects.

We developed and applied a mechanism-based PK/PD/ pharmacogenomic model with circadian-controlled processes that describes the tissue-specific dynamics of GILZ mRNA expression in skeletal muscle, lung, and white adipose tissue. The GILZ and GR mRNA dynamics were examined in intact (non-ADX) rats to evaluate concerted effects of circadian rhythms and CS pharmacodynamics. The mechanistic model was fitted simultaneously to data from untreated and single-dosed animals to yield tissue-specific information on drug- and system-specific parameters. Simulations were performed to predict the GILZ mRNA dynamics in lung and adipose tissue upon chronic dosing and to gain new insights into the tissue- and dose regimen-dependent aspects controlling receptor-mediated gene expression in vivo. Collectively, these studies provide a quantitative and mechanistic framework for the application of GILZ as a PD marker of a CS anti-inflammatory mediator in tissues of clinical relevance.

\section{Materials and Methods}

\section{Animals}

Experiments used tissue samples harvested from three separate population-based animal studies conducted in our laboratory. An extensive description of these studies can be found in previously published reports (Hazra et al., 2007a; Almon et al., 2008; Ayyar et al., 2015). Brief descriptions of the studies are provided here. In all studies, normal male Wistar rats were acclimated and housed under a 12-hour:12-hour light:dark cycle and constant-temperature $\left(22^{\circ} \mathrm{C}\right)$ environment, with free access to drinking water and standard rat chow. All animals were housed in separate cages to facilitate animal manipulations while minimizing stress to the animals. The rats were euthanized by aortic exsanguination under ketamine/xylazine anesthesia $(80: 10 \mathrm{mg} / \mathrm{kg})$. Blood samples were harvested using EDTA as an anticoagulant. Plasma was prepared from blood by centrifugation (2000g, $4^{\circ} \mathrm{C}, 15$ minutes), aliquoted, and stored at $-80^{\circ} \mathrm{C}$ until further analyses. Several tissues, including abdominal adipose, lung, and skeletal muscle, were rapidly excised, flash frozen in liquid nitrogen, and stored at $-80^{\circ} \mathrm{C}$. Animals euthanized at the same time point were treated as triplicate measurements in each study. All animal study protocols adhered to the "Guide for the Care and Use of Laboratory Animals, 8th Edition" and were approved by the State University of New York at Buffalo Institutional Animal Care and Use Committee.

\section{Experimental}

Circadian Study. Fifty-four normal male Wistar rats purchased from Harlan Laboratories (Indianapolis, IN) were housed and allowed to acclimatize in a room equipped with a 12-hour light/dark cycle, and were subject to minimal environmental disturbance. Animals were euthanized by exsanguination on three successive days at 18 different time points ranging from 15 minutes to 23.75 hours after lights went on ( $n=3$ animals per time point).

Single Methylprednisolone Bolus Study. Sixty normal male Wistar rats purchased from Harlan Laboratories were used. Each animal was given a single $50-\mathrm{mg} / \mathrm{kg}$ IM bolus dose of methylprednisolone sodium succinate (Solu-Medrol; Upjohn, Kalamazoo, MI) in the left hind haunch between 1.5 and 3 hours after lights on (i.e., at the nadir of the circadian pattern of the endogenous CST rhythm). Animals were euthanized at 18 different time points ranging from 15 minutes to 4 days (96 hours) after receiving methylprednisolone (MPL) injection $(n=$ 3 animals per time point). Control animals were euthanized in triplicate at 12 and 24 hours after saline injection.

Chronic MPL Infusion Study. Thirty-nine normal male Wistar rats were purchased from Harlan-Sprague Dawley Inc. (Indianapolis, IN). The treatment group ( $n=27)$ were given $0.3 \mathrm{mg} / \mathrm{kg} / \mathrm{h}$ methylprednisolone sodium succinate (Solu-Medrol) via SC implanted Alzet osmotic minipumps (Model 2001; Alza, Palo Alto, CA). Animals in the control group $(n=12)$ were implanted with vehicle-filled pumps. MPLdosed animals were euthanized over 7 days following pump implantation ( $n=3$ animals per time point). Vehicle controls were euthanized at $6,12,18$, and 24 hours after pump implantation $(n=3$ animals per time point).

\section{Drug and Endogenous Steroid Assay}

Plasma CST and MPL concentrations were determined by a normalphase high-performance liquid chromatography method (Haughey and Jusko, 1988). The limit of quantitation was $5 \mathrm{ng} / \mathrm{ml}$ for CST and $10 \mathrm{ng} / \mathrm{ml}$ for MPL. The interday and intraday coefficients of variation (CVs) were less than $10 \%$.

\section{RNA Preparation}

Frozen tissue samples were ground into a fine powder under liquid nitrogen. Powdered samples were weighed, added to prechilled TRI Reagent (Invitrogen, Carlsbad, CA), and homogenized. Total RNA extractions were carried out using TRI Reagent and further purified by passage through RNeasy minicolumns (Qiagen, Valencia, CA) according to the manufacturer's protocols for RNA cleanup. The RNA concentrations were quantified spectrophotometrically (NanoDrop 2000c; Thermo Fisher Scientific, Waltham, MA), and purity and integrity were assessed by agarose-formaldehyde gel electrophoresis. All samples exhibited 260/280 absorbance ratios of approximately 2.0, and all showed intact ribosomal $28 \mathrm{~S}$ and $18 \mathrm{~S}$ RNA bands in 
an approximate ratio of 2:1 as visualized by ethidium bromide staining. Final total RNA preparations were diluted to desired concentrations in nuclease-free water (Ambion, Austin, TX) and stored in nuclease-free tubes at $-80^{\circ} \mathrm{C}$ until use.

\section{Quantification of mRNA Expression}

The GILZ- and GR-specific quantitative real-time reverse transcription polymerase chain reaction (qRT-PCR) assays were developed and validated according to the Minimum Information for Publication of Quantitative Real-Time PCR Experiments guidelines (Bustin et al., 2009). Both qRT-PCR assays involved use of in vitro transcribed cRNA standards, gene-specific TaqMan-based probes, and a single-step assay. An extensive description of the subcloning and construction of the in vitro transcribed cRNA standards was reported previously (Ayyar et al., 2015). Primer and probe sequences were designed and custom-synthesized (Biosearch Technologies, Novato, CA). qRT-PCR was performed using a Brilliant qRT-PCR Core Reagent Kit, 1-Step (Stratagene, La Jolla, CA) in a Stratagene MX3005P thermocycler according to the manufacturer's instructions. Primer and probe sequences were as follows: GR, forward primer 5'-AACATGTTAGGTGGGCGTCAA-3', reverse primer 5'GGTGTAAGTTTCTCAAGCCT AGTATCG-3', and 6-carboxyfluoresceinlabeled probe 5'-TGATTGCAGCAGTGAAATGGGCAAAG-3'; GILZ, forward primer 5'-GGAGGTCCTAAAGGAGCAGATTC-3', reverse primer 5'-GCGTCTTCAGGAGGG TATTCTC-3', and 6-carboxyfluorescein-labeled probe, $5^{\prime}$-TGAGCTGGTTGAGAAGAACTCGCA3 '. Standards were run in duplicate and samples in triplicate; intra- and interassay CVs were less than $20 \%$. Additional reverse transcriptases minus controls were included to ensure lack of DNA contamination in each sample.

\section{Pharmacokinetic/Pharmacodynamic/Pharmacogenomic Modeling}

Pharmacokinetics. A two-compartment model with dual absorption pathways from the injection site was used to describe the PK of IM dosing of MPL (Hazra et al., 2007b). The PK parameters were fixed with estimates obtained from our previous study, as given in Table 1. Equations and initial conditions (IC) describing the model are:

$$
\begin{array}{rr}
V_{P} \frac{d C_{p}}{d t}= & k_{a 1} \cdot D_{(I M)} \cdot F \cdot F_{r} \cdot e^{-k_{a 1} t}+k_{a 2} \cdot D_{(I M)} \cdot F \cdot\left(1-F_{r}\right) \cdot e^{-k_{a 2} t} \\
-C L \cdot C_{P}-C L_{D} \cdot C_{P}+C L_{D} \cdot C_{T} & \mathrm{IC}=0 \\
V_{T} \frac{d C_{T}}{d t}=C L_{D} \cdot C_{P}-C L_{D} \cdot C_{T} & \mathrm{IC}=0
\end{array}
$$

where $C$ and $D$ represent the concentration and dose of MPL in the corresponding plasma $(P)$ and tissue $(T)$ compartments, $F_{r}$ and $\left(1-F_{r}\right)$ are fractions of dose absorbed through the absorption pathways described by first-order rate constants $k_{a 1}$ and $k_{a 2}, C L$ is clearance from the central compartment, $C L_{D}$ is the distribution clearance, $F$ is the overall bioavailability of MPL after IM injection, and $V_{P}$ and $V_{T}$ are the central and peripheral volumes of distribution.

The same equations were used for the SC infusion kinetics, with the exception that a zero-order input function $(0.3 \mathrm{mg} / \mathrm{kg} / \mathrm{h})$ was applied instead of the two first-order absorption terms. Distributionrelated parameters $\left(V_{P}, V_{T}\right.$, and $\left.C L_{D}\right)$ were fixed based on the bolus data, whereas the $C L$ was estimated from the infusion data. The pharmacokinetic model schematic for both dosing regimens is depicted in Fig. 1. Plasma drug concentrations over time were fixed and used as a driving force for the dynamics in the subsequent data analysis.

\section{Mechanistic Basis for Pharmacodynamics}

The diverse cellular and molecular processes that govern the pharmacodynamic and pharmacogenomic effects of CS are depicted in Fig. 2. Approximately $77 \%$ of circulating CS in plasma is bound to corticosteroid-binding globulin (CBG) and albumin (Haughey and Jusko, 1992). Owing to its moderate lipophilicity, free (unbound) CS can passively diffuse across cell membranes into the cytosol, where the GR is located. Inactive GR is held and stabilized in the cytoplasm by molecular chaperones including heat shock proteins (hsp70 and hsp90) as well as the FK506-binding protein immunophilins (Pratt and Toft, 1997). The CS bind to cytoplasmic GR and cause a dissociation of the chaperone complex by inducing a conformational change in the GR molecule. Upon dissociation from chaperone proteins, activated drug-receptor complexes rapidly translocate into the nucleus and homodimerize. The complexes then bind specific DNA sequences known as GREs in the 5 '-upstream promoter regions of target genes, leading to transcriptional changes by altering the chromatin structure (Newton, 2000; Barnes, 2006) and consequent activation of the RNA-polymerase complex. This genome-level interaction positively or negatively regulates the expression of a plethora of genes. De novo synthesized RNA transcripts undergo 5 '-capping, splicing, and 3 '-polyadenylation to form mRNA, which are exported to the cytoplasm. mRNA transcripts-in this case, those encoding GILZ - are then translated into protein and/or degraded within the cytoplasm, leading to alterations in measurable mRNA and protein concentrations.

After exerting their transcriptional effects, the steroid-receptor complexes in the nucleus may dissociate from GREs and return to the cytosol. Part of the receptors may be degraded during the process, whereas the rest may be reassembled with chaperone proteins and recycled. Therefore, the total pool of free cytosolic GR constitutes a composite of recycled and de novo synthesized GR molecules. Furthermore, the CS cause homologous downregulation of their own receptors via decreased transcription, which subsequently results in decreased mRNA synthesis and free GR densities in the cytosol (Oakley and Cidlowski, 1993; DuBois et al., 1995).

\section{Mathematical Model}

Figure 3 depicts the integrated PK/PD/pharmacogenomic model that describes the tissue-specific effects of CS and circadian oscillations on the regulation of GILZ gene expression.

\section{Glucocorticoid Receptor Dynamics}

The dynamics of GR have been previously studied in liver and adipose tissue from normal male rats (Hazra et al., 2008; Sukumaran et al., 2011). Kinetic parameter values governing drug-receptor binding, translocation, and recycling were fixed to previously obtained values (Hazra et al., 2007a) since these processes are considered to be

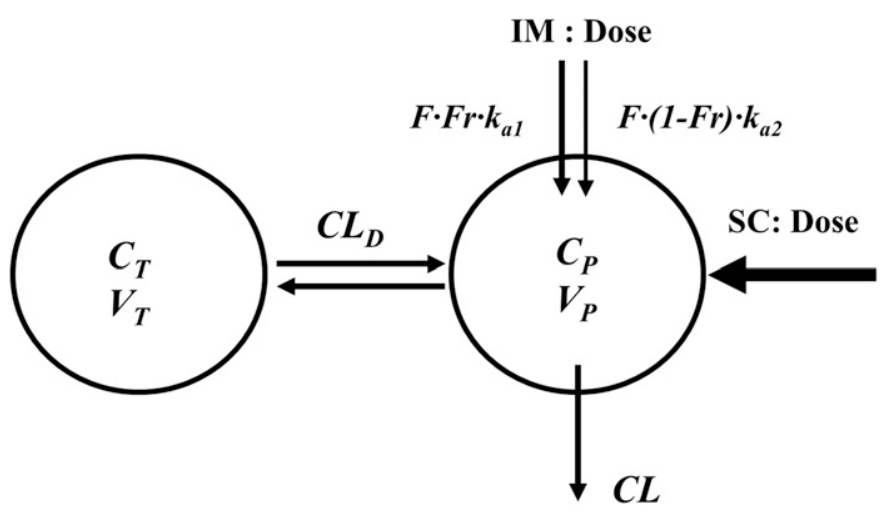

Fig. 1. Pharmacokinetic model for methylprednisolone with dose input either as an intramuscular injection (IM) or a subcutaneous infusion (SC); the symbols are defined in the text and Table 1 . The model is described by eqs. 1 and 2. 


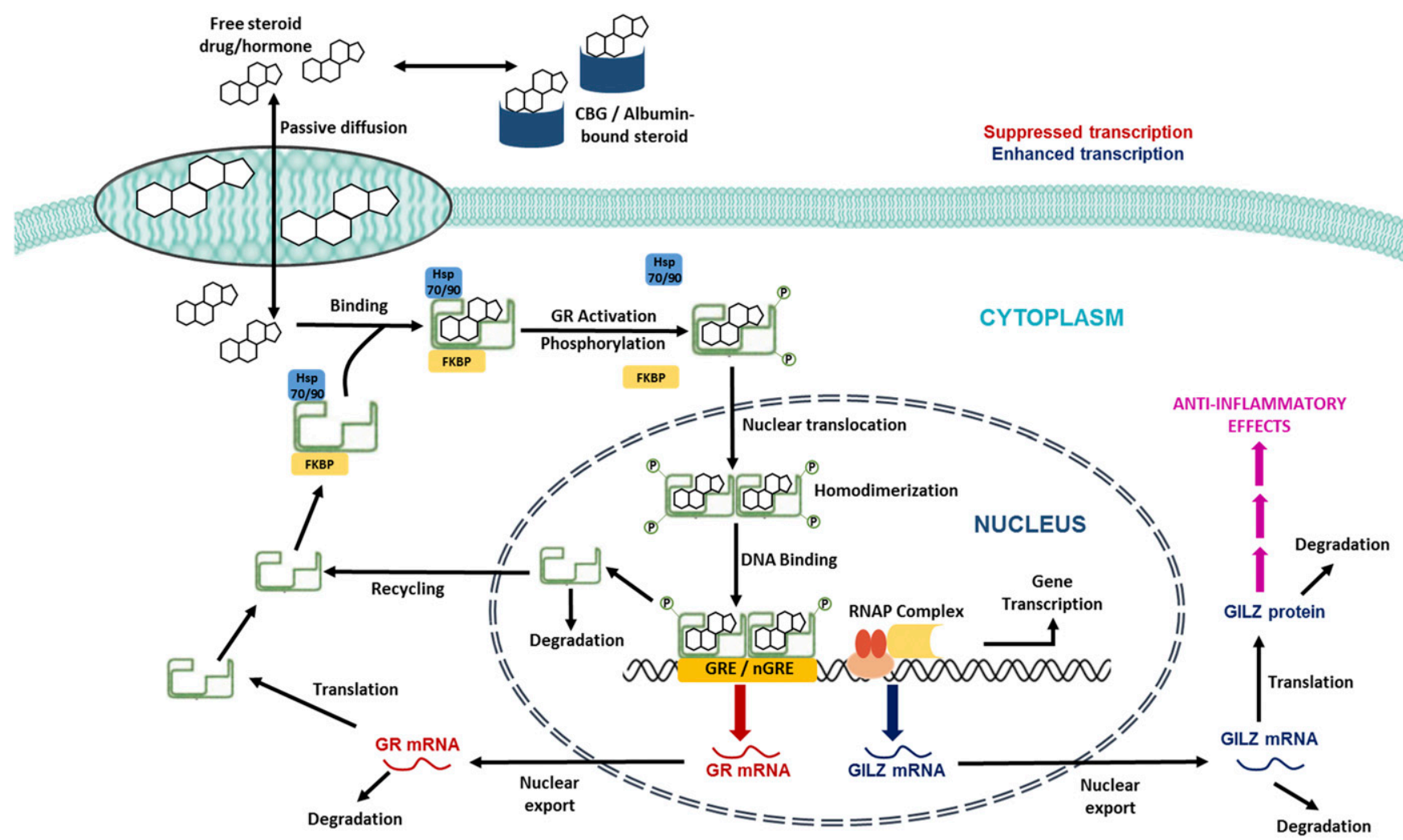

Fig. 2. Schematic representation of diverse molecular and cellular mechanisms of corticosteroid action on regulating gene expression. CBG, corticosteroidbinding globulin; FKBP, FK506 binding protein; hsp 70/90, heat shock protein 70/90; nGRE, negative glucocorticoid response element; RNAP, RNA polymerase.

similar across different tissues. The differential equations and initial conditions for GR dynamics in the tissues are:

$$
\begin{array}{cc}
\frac{d R}{d t}=k_{s, G R} \cdot G R_{m}-k_{d, G R} \cdot R-k_{\text {on }} \cdot f_{m p l} \cdot C_{m p l} \cdot R+k_{r e} \cdot R_{f} \cdot D R_{n} & \mathrm{IC}=R(0) \\
\frac{d D R}{d t}=k_{o n} \cdot f_{m p l} \cdot C_{m p l} \cdot R-k_{t} \cdot D R & \mathrm{IC}=D R(0) \\
\frac{d D R_{n}}{d t}=k_{t} \cdot D R-k_{r e} \cdot D R_{n} & \mathrm{IC}=D R_{n}(0)
\end{array}
$$

where $R$ is the free cytosolic receptor, $D R$ is the cytosolic drugreceptor complex, and $D R_{n}$ is the nuclear translocated drug-receptor complex concentrations. The rate constants include receptor synthesis $\left(k_{s, G R}\right)$ and degradation $\left(k_{d, G R}\right)$, translocation of the drug-receptor complex into the nucleus $\left(k_{T}\right)$, the overall turnover of $D R_{n}$ return receptors to cytosol $\left(k_{r e}\right)$, as well as the second-order rate constant of drug-receptor association $\left(k_{o n}\right)$. Part of $D R_{n}$ may recycle back to the cytosol controlled by the rate constant $R_{f} k_{r e}$, and the rest is degraded with a rate constant $\left(1-R_{f}\right) \cdot k_{r e}$. The $f_{m p l}$ is the unbound fraction of MPL in plasma.

The GR mRNA $\left(G R_{m}\right)$ showed circadian oscillations in muscle, lung, and adipose, which were described using an indirect response (IDR) model with the mRNA synthesized by a time-dependent synthesis rate $\left(k_{s, G R m(t)}\right)$ and degraded by first-order rate constant $\left(k_{d, G R m}\right)$ as follows:

$$
\frac{d G R_{m}}{d t}=k_{s, G R m}(t)-k_{d, G R m} \cdot G R_{m} \quad \mathrm{IC}=G R_{m}(0)
$$

The time-dependent synthesis rate of GR mRNA $\left[k_{s, G R m(t)}\right]$ in adipose tissue was described using a two-harmonic function as

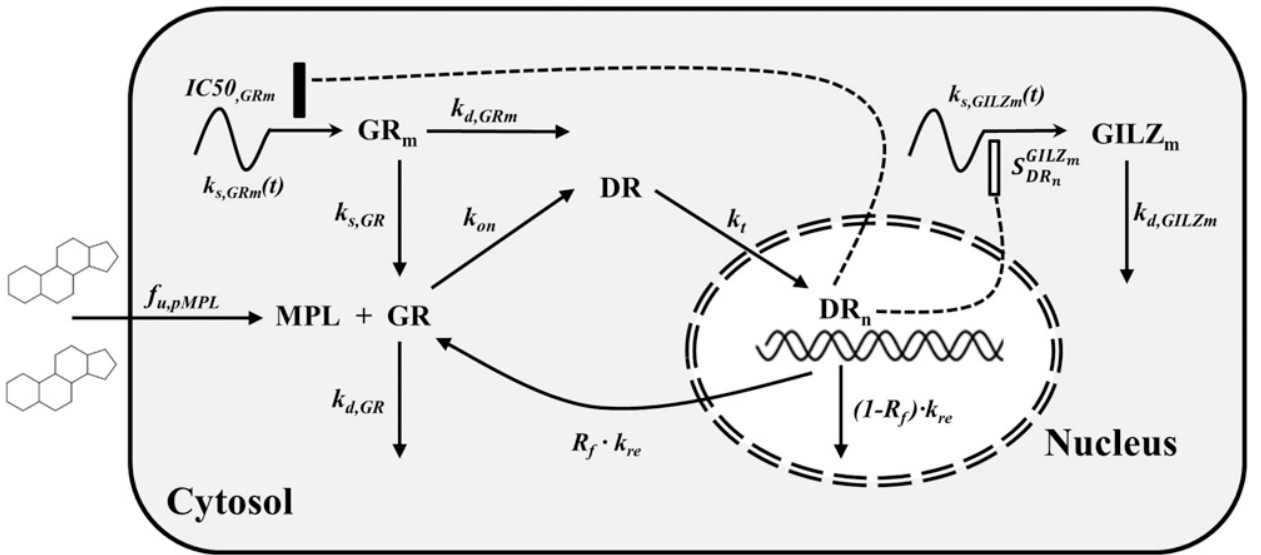

Fig. 3. PK/PD model schematic for the pharmacogenomic effects of corticosteroids and circadian rhythms on the transcriptional regulation of GILZ mRNA expression. Curved input represents circadian pattern in production, open boxes reflect stimulation, and solid boxes depict inhibition of production rate of a turnover process. The model is described by eqs. 3-12. Parameters are defined in Tables 2 and 3. 
reported previously (Sukumaran et al., 2011), whereas singleharmonic functions were applied for the same in skeletal muscle and lung:

$$
\begin{aligned}
k_{s, \text { GRm,adipose }}(t)= & a_{0, G R m} \cdot k_{d, G R m} \\
+ & \left(a_{1, G R m} \cdot k_{d, G R m}+\frac{2 \pi b_{1, G R m}}{24}\right) \cdot \cos \left(\frac{2 \pi T}{24}\right) \\
+ & \left(b_{1, G R m} \cdot k_{d, G R m}+\frac{2 \pi a_{1, G R m}}{24}\right) \cdot \sin \left(\frac{2 \pi T}{24}\right) \\
+ & \left(a_{2, G R m} \cdot k_{d, G R m}+\frac{2 \pi b_{2, G R m}}{12}\right) \cdot \cos \left(\frac{2 \pi T}{12}\right) \\
+ & \left(b_{2, G R m} \cdot k_{d, G R m}+\frac{2 \pi a_{2, G R m}}{12}\right) \cdot \sin \left(\frac{2 \pi T}{12}\right) \\
k_{s, G R m, l \text { lung } / \text { muscle }}(t)= & a_{0, G R m} \cdot k_{d, G R m} \\
& +\left(a_{1, G R m} \cdot k_{d, G R m}+\frac{2 \pi b_{1, G R m}}{24}\right) \cdot \cos \left(\frac{2 \pi T}{24}\right) \\
& +\left(b_{1, G R m} \cdot k_{d, G R m}+\frac{2 \pi a_{1, G R m}}{24}\right) \cdot \sin \left(\frac{2 \pi T}{24}\right)
\end{aligned}
$$

where $a_{i}$ and $b_{i}$ are Fourier coefficients associated with the harmonic oscillations. Values for these parameters were obtained by fitting the replicate GR mRNA expression data measured in each tissue from the circadian control study using the FOURPHARM program (Krzyzanski et al., 2000).

Suppression in GR mRNA expression by MPL is given by:

$$
\begin{aligned}
\frac{d G R_{m, m p l}}{d t} & =k_{s, G R m(t)} \cdot\left[1-\left(\frac{D R_{n}}{D R_{n}+I C_{50, G R m}}\right)\right] \\
& -k_{d, G R m} \cdot G R_{m, m p l} \quad \text { IC }=G R_{m, m p l}(0)
\end{aligned}
$$

where the $I C_{50, G R m}$ is the concentration of $D R_{n}$ at which the synthesis rate of GR mRNA is reduced to $50 \%$ of its baseline. Measures of GR mRNA expression $\left(G R_{m}\right)$ following MPL dosing in adipose tissue (Sukumaran et al., 2011), lung, and skeletal muscle were used to infer the concentrations of free cytosolic receptor density $(R)$ in those tissues based on eq. (3).

\section{Circadian Rhythm of GILZ mRNA Expression}

The GILZ mRNA displays circadian oscillations, which is under the complex regulation of CST as well as the peripheral circadian clock gene loop present in tissues (Ayyar et al., 2015; Soták et al., 2016). Circadian rhythms in GILZ mRNA expression in tissues were modeled using an IDR model with a time-dependent synthesis rate $\left[k_{s, G I L Z m(t)}\right]$, described by a single harmonic function and degraded by a first-order rate constant $\left(k_{d, G I L Z m}\right)$ as:

$$
\begin{aligned}
& \frac{d G I L Z_{m}}{d t}=k_{s, G I L Z m}(t)-k_{d, G I L Z m} \cdot G I L Z_{m} \quad \text { IC }=\operatorname{GILZ}_{m}(0) \\
& k_{s, G I L Z m}(t)= a_{0, G I L Z m} \cdot k_{d, G I L Z m} \\
&+\left(a_{1, G I L Z m} \cdot k_{d, G I L Z m}+\frac{2 \pi b_{1, G I L Z m}}{24}\right) \cdot \cos \left(\frac{2 \pi T}{24}\right) \\
&+\left(b_{1, G I L Z m} \cdot k_{d, G I L Z m}+\frac{2 \pi a_{1, G I L Z m}}{24}\right) \cdot \sin \left(\frac{2 \pi T}{24}\right)
\end{aligned}
$$

where $a_{i}$ and $b_{i}$ are Fourier coefficients associated with the harmonic oscillations. The values for these parameters were obtained by fitting the replicate GILZ mRNA expression data measured in tissues from the circadian control study using FOURPHARM.

\section{Enhancement of GILZ mRNA Expression by CS}

Transcriptional up-regulation of GILZ by CS has been documented in multiple cell types (D'Adamio et al., 1997; Eddleston et al., 2007; Aguilar et al., 2013). The pharmacogenomic effects of acute and chronic MPL dosing on GILZ mRNA expression in skeletal muscle, lung, and adipose tissue were modeled as a direct stimulation of the mRNA synthesis rate by the activated drug-receptor complex in the nucleus $\left(D R_{n}\right)$ controlled by the stimulation constant, $S_{D R n}{ }^{G I L Z m}$ as:

$$
\begin{array}{r}
\frac{d G I L Z_{m, m p l}}{d t}=k_{s, G I L Z m}(t) \cdot\left(1+S_{D R_{n}}^{G I L Z m} \cdot D R_{n}\right)- \\
\text { IC }=G I L Z_{m, m p l}(0)
\end{array}
$$

Data Analysis. The ADAPT 5 software was used for all data fitting and simulation of model equations (D'Argenio et al., 2009). The maximum likelihood method was applied for fitting the data. Replicate data at each time point from animals in each experiment were naïve-pooled, and data from both circadian control and single-dose experiments were modeled simultaneously. Replicate data from the chronic MPL infusion study served as an external model validation set. The goodness of fit was assessed by system convergence, visual inspection of the fitted curves, objective function values such as Akaike information criterion (AIC), improved likelihood, examination of residuals, and precision (CV\%) of the estimated parameters. The following variance model was used for the model fitting:

$$
V_{i}=V(\theta, \sigma, t)=\left[\sigma_{1}+\sigma_{2} \cdot Y\left(\theta, t_{i}\right)\right]^{2}
$$

where $V\left(\sigma, \theta, t_{i}\right)$ is the variance for the $i$ th point, $Y\left(\theta, t_{i}\right)$ is the $i$ th model-predicted value, $\theta$ represents the estimated structural parameters, and $\sigma_{1}$ and $\sigma_{2}$ are the variance parameters that were estimated.

Animals in the dosing experiments were given MPL between 1.5 and 3 hours after lights on. For simplicity, the dosing time was assumed to be at circadian time 2.5 hours to compare the data obtained from both the MPL-dosing and circadian experiments. Hence, all pharmacodynamic profiles are plotted with respect to circadian time, with MPL given at 2.5 hours.

\section{Results}

Pharmacokinetics. The plasma concentration-time profiles of MPL following IM bolus and SC infusion regimens are shown in Fig. 4. The PK profile of IM dosed MPL was simulated using parameter estimates obtained from a previously conducted PK study (Hazra et al., 2007b). MPL is known to undergo nonlinear interconversion as well as extensive hepatic oxidative metabolism in rats (Kong and Jusko, 1991). Further, plasma protein binding is relatively constant $\left(f_{m p l}=77 \%\right)$ with concentration (Haughey and Jusko, 1992). Steady-state concentrations of MPL in the infusion study were roughly 100 -fold lower compared with those in previous bolus studies (Sun et al., 1998; Hazra et al., 2007b). Therefore, $C L$ was estimated from the infusion data. The first sampling time in the infusion study was at 6 hours after starting the infusion; by then, MPL had achieved steady-state concentrations. Thus, the rising phase of the PK profile, which provides information regarding drug absorption and distribution, was unavailable. Hence, the distribution clearance and volumes of distribution were fixed based on the previous bolus estimates (Hazra et al., 2007b). In addition, drug absorption from the SC site was assumed to be complete and rapid compared with the rate of drug release from the pump. MPL clearance increased from 4.0 to $8.3 \mathrm{l} / \mathrm{h} / \mathrm{kg}$, which suggests that high concentrations of MPL cause saturation of drug-metabolizing enzymes. The PK parameters describing the data for both dosing regimens are listed in Table 1.

Circadian Dynamics of GR mRNA Expression. The daily fluctuation of receptor mRNA was examined in skeletal muscle and lung obtained from normal animals housed under 


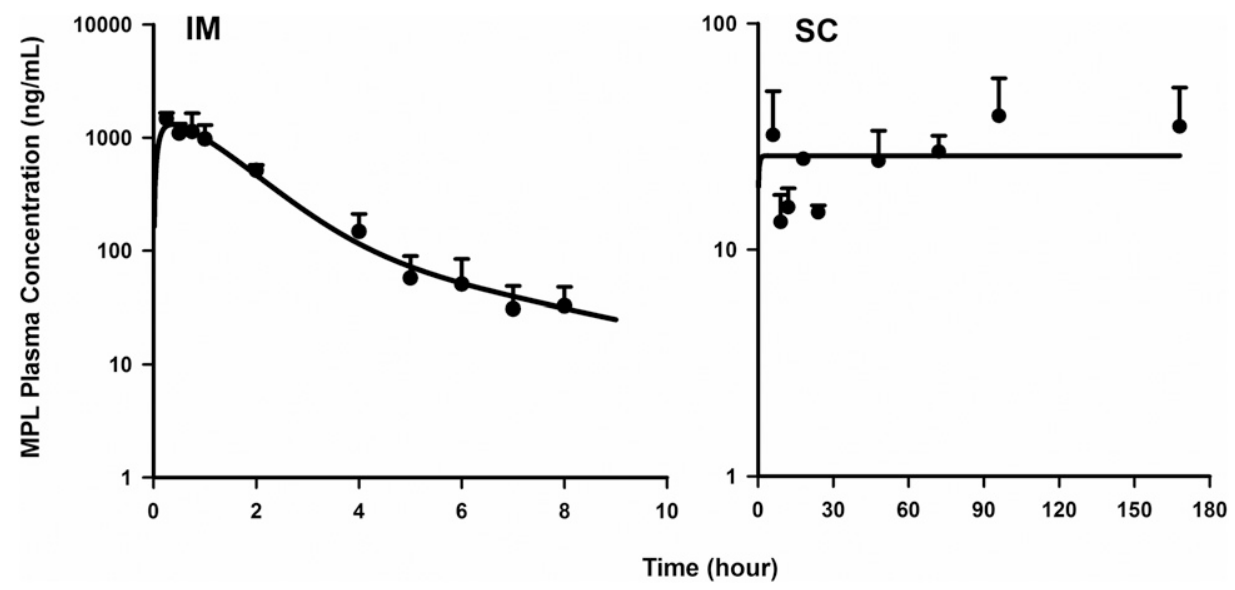

Fig. 4. MPL pharmacokinetics in rats. Simulated plasma concentrations versus time after $50 \mathrm{mg} / \mathrm{kg}$ intramuscular (IM) injection of MPL using eqs. 1 and 2. Pharmacokinetics of MPL upon administration of $0.3-\mathrm{mg} / \mathrm{kg} / \mathrm{h}$ subcutaneous (SC) infusion for 7 days. Solid lines represent model fittings, circles depict the mean, and error bars depict 1 standard deviation $(n=3)$

tightly controlled 12-hour light/12-hour dark cycles. The profile for adipose tissue was simulated based on previous data collected from the same set of animals (Sukumaran et al., 2011). The circadian dynamics of tissue-specific GR mRNA along with the model fittings are presented in Fig. 5 .

Message expression in skeletal muscle (Fig. 5) showed a modest circadian rhythm, starting at $1164 \pm 66$ molecules/ng RNA in the light phase, with a nadir at the transition from the light to dark period (around 800 molecules/ng RNA) at 12 hours, before gradually increasing through the dark period. This pattern was well described by a single harmonic function. The baseline receptor mRNA expression was approximately 3 -fold higher in lung compared with skeletal muscle (Fig. 5). Furthermore, lung GR exhibited a circadian pattern distinct from muscle, showing a nadir in the light phase at 7 hours and a peak in the dark phase around 18 hours, which was also adequately described by a single harmonic function. Interestingly, the observed patterns of receptor message in skeletal muscle and lung also varied from that observed in adipose tissue (Fig. 5), where the circadian oscillations peaked at the transition from the light to dark period at time 12 hours, which was described by a two-harmonic Fourier function (Sukumaran et al., 2011).

GR mRNA Dynamics upon Acute MPL Dosing. Dynamics of GR mRNA expression following acute CS dosing were measured in muscle and lung, and simulated in adipose tissue based upon a previous report (Sukumaran et al., 2011). The dynamics of GR mRNA suppression in each tissue along with the model fittings are shown in Fig. 6. MPL caused significant down-regulation in GR mRNA expression by $45 \%-$ $80 \%$ in skeletal muscle, lung, and adipose tissue, with the nadirs occurring between 6 and 9 hours after MPL dosing.

TABLE 1

Pharmacokinetic parameters of methylprednisolone

\begin{tabular}{llc}
\hline \multicolumn{1}{c}{ Parameter } & \multicolumn{1}{c}{ Definition } & Estimate $(\mathrm{CV} \%)$ \\
\hline$F$ & Bioavailability & $0.214^{a, b} / 1.0^{c}$ \\
$F r$ & Fraction absorbed by $k_{a 1}$ & $0.73^{a, b} / \mathrm{NA}^{c}$ \\
$k_{a 1}\left(\mathrm{~h}^{-1}\right)$ & Absorption rate constant & $1.26^{a, b} / \mathrm{NA}^{c}$ \\
$k_{a 2}\left(\mathrm{~h}^{-1}\right)$ & Absorption rate constant & $0.22^{a, b} / \mathrm{NA}^{c}$ \\
$V_{P}(\mathrm{ml} / \mathrm{kg})$ & Plasma volume of distribution & $718.7^{a, b, c}$ \\
$V_{T}(\mathrm{ml} / \mathrm{kg})$ & Tissue volume of distribution & $913.5^{a, b, c}$ \\
$C L_{D}(\mathrm{l} / \mathrm{h} / \mathrm{kg})$ & Distribution clearance & $2.6^{a, b, c}$ \\
$C L(\mathrm{l} / \mathrm{h} / \mathrm{kg})$ & Clearance & $4.0^{a, b} / 8.3^{c}(10.1)$ \\
\hline
\end{tabular}

${ }^{a}$ Intramuscular parameter values fixed from Hazra et al. (2007b).

${ }^{b} 50 \mathrm{mg} / \mathrm{kg}$ IM bolus.

${ }^{c} 0.3 \mathrm{mg} / \mathrm{kg} / \mathrm{h}$ SC infusion.
About $45 \%-50 \%$ suppression in muscle receptor mRNA expression was observed at the nadir after MPL dosing, which returned to the rhythmic baseline by 24 hours (Fig. 6). The estimated degradation-rate constant $\left(k_{d, G R m}\right)$ value of 0.28 hour $^{-1}$ (29.9 CV\%) in skeletal muscle was higher than the value of 0.14 hour $^{-1}$ reported in muscle from ADX rats (Sun et al., 1999). The nadir occurred around 7-8 hours after MPL versus 10-11 hours in the ADX rats, which could be attributed to the higher $k_{d, G R m}$ in the normal animals. Acute MPL dosing led to about $60 \%$ suppression in lung GR mRNA at the nadir around 7-9 hours and returned to baseline expression by 24 hours after MPL (Fig. 6), which was well described by the model. It can be noted that GR mRNA at the early time points in the treatment group was higher than expression observed upon return to baseline after MPL, which was similar to GR expression in the circadian controls. The estimated degradationrate constant $\left(k_{d, G R m}\right)$ value of 0.26 hour $^{-1}(15.4$ CV\%) was similar to that obtained in skeletal muscle $\left(0.28\right.$ hour $\left.^{-1}\right)$ and in white adipose tissue $\left(0.31\right.$ hour $^{-1}$ ) (Sukumaran et al., 2011), but lower than the reported value of 0.12 hour $^{-1}$ in liver (Hazra et al., 2007a). Furthermore, the nadir in receptor mRNA expression after MPL dosing was reached around the same time as in both muscle and adipose tissue, which could be attributed to similar $k_{d, G R m}$ values.

The suppression of GR mRNA expression by MPL in adipose tissue has been modeled previously (Sukumaran et al., 2011). Therefore, relevant parameter estimates were fixed to simulate the adipose tissue profile (Fig. 6). Tissue-specific rates of receptor synthesis $\left(k_{s, G R}\right)$ and free cytosolic receptor densities at baseline $[G R(0)]$ were also estimated using the dynamics of GR mRNA expression in the tissues. Table 2 provides the parameter estimates related to GR dynamics.

Circadian Dynamics of GILZ mRNA Expression. Endogenous cyclic regulation of GILZ mRNA expression was examined in skeletal muscle, lung, and adipose obtained from normal untreated animals. The dynamics of circadian oscillations in GILZ mRNA expression in all three tissues along with the model fittings are shown in Fig. 7. Superimposed on these figures is the profile of CST measured in plasma from the same animals. In all three tissues, GILZ mRNA regulation in vivo follows a pattern that is entrained to that of the CST rhythm.

Fig. 7 shows the circadian mRNA expression profile of GILZ in skeletal muscle. Interestingly, a prominent delay in peak (9330 \pm 273 molecules/ng RNA) and trough (4350 \pm 743 molecules/ng RNA) expression was observed compared 

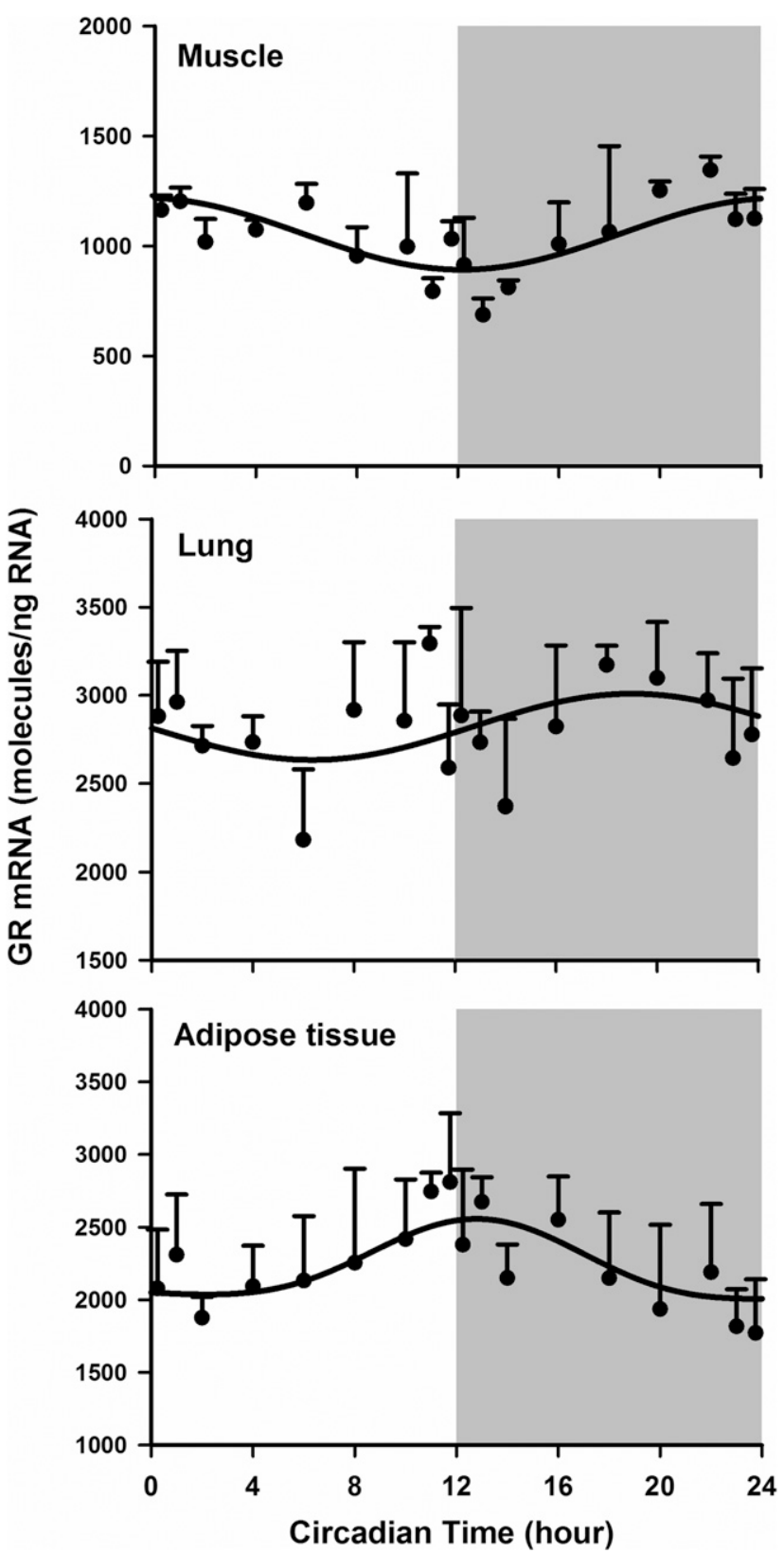

Fig. 5. Circadian rhythm of GR mRNA expression in three tissues from baseline-control animals. Circles represent the mean and error bars, 1 standard deviation $(n=3)$. The solid line depicts the fitting results using the PK/PD model depicted in Fig. 3. Unshaded regions depict the light phase and shaded regions, dark phase of the 24 -hour cycle.

with lung and adipose tissue (Fig. 7). Specifically, GILZ mRNA expression peaked at 20 hours and showed a nadir around 9-10 hours. The model well captured the trend of the circadian profile. In both lung and adipose, GILZ mRNA peaked in the dark period $(18,867 \pm 2347$ molecules/ng RNA for adipose and 25,202 \pm 1145 molecules/ng RNA for lung) at 16 hours and showed a trough in the light period (4446 \pm 622 molecules/ng RNA for adipose and $5141 \pm 615$ molecules/ng RNA for lung) around 6-8 hours. Circadian rhythmicity in GILZ mRNA expression was strongest in lung compared with the other tissues. Although the model predicts peak expression around 17 hours, the data are captured reasonably well by the single Fourier harmonic function.
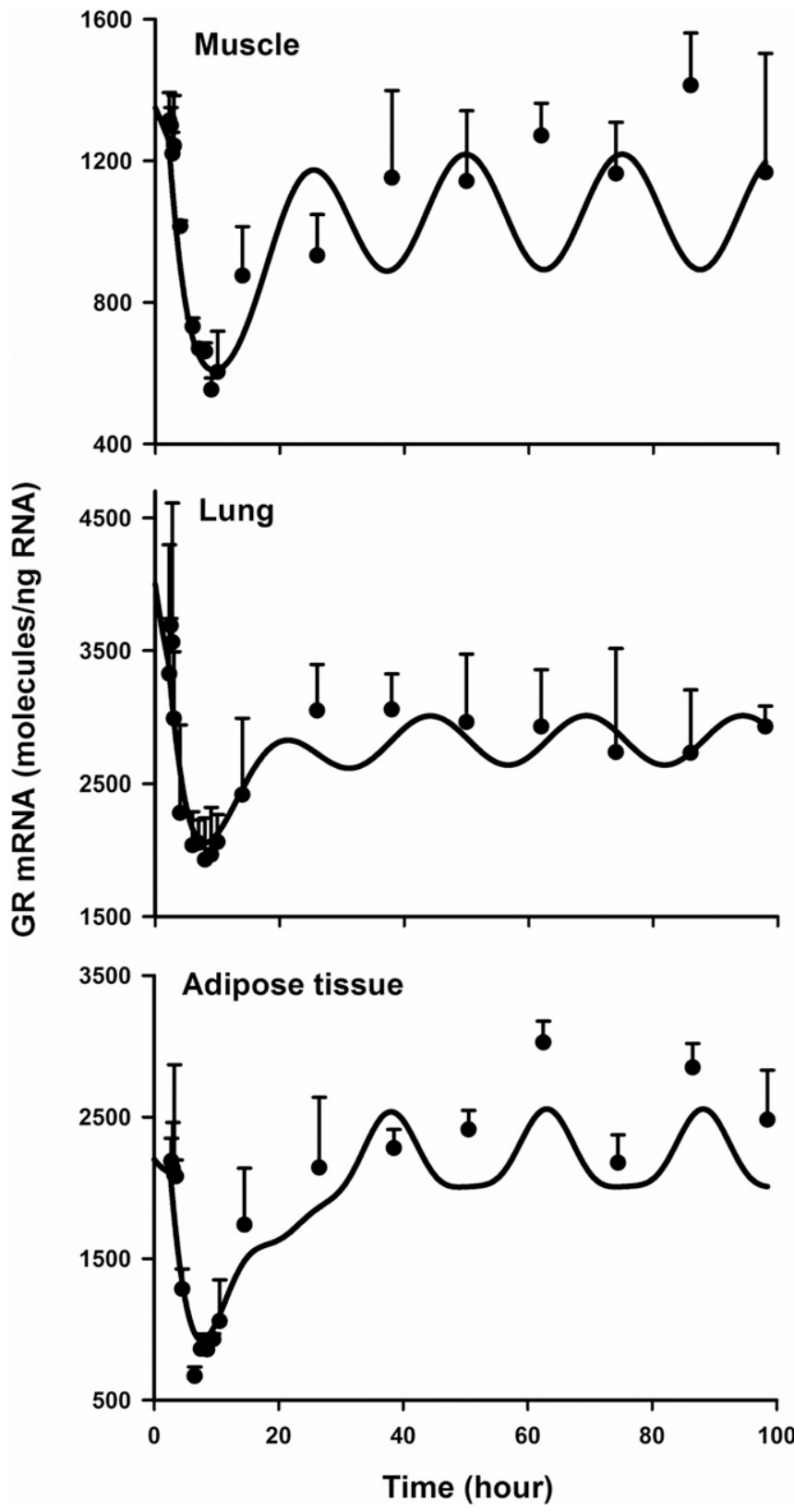

Fig. 6. GR mRNA expression in three tissues from rats given $50 \mathrm{mg} / \mathrm{kg}$ IM MPL. Circles represent the mean and error bars, 1 standard deviation $(n=$ 3 ). The solid line depicts the fitting using the PK/PD model depicted in Fig. 3 and parameter estimates listed in Table 2.

GILZ mRNA Dynamics upon Acute MPL Dosing. CS such as dexamethasone cause strong up-regulation of GILZ mRNA expression in vitro (D'Adamio et al., 1997; Smit et al., 2005; Aguilar et al., 2013). Since basal expression of GILZ mRNA shows a circadian pattern in vivo, transcriptional enhancement of GILZ by exogenous CS must be interpreted within this context. As shown in Fig. 8, the response of GILZ to MPL dosing clearly exceeded normal circadian variation in all tissues. Up-regulation of GILZ mRNA was observed as early as 15 minutes after dosing and continued to rise to peak values as late as 8 hours, when plasma MPL concentrations continued to decline. GILZ mRNA eventually re-established its circadian rhythm in all tissues following perturbation by MPL. The 
TABLE 2

Parameter values for GR mRNA expression and receptor dynamics

\begin{tabular}{llc}
\hline \multicolumn{1}{c}{ Parameter } & \multicolumn{1}{c}{ Definition } & Estimate (CV\%) \\
\hline$a_{O, G R m}$ & Fourier coefficient for GR mRNA & $2824^{a} / 1055.9^{b} / 2216^{c, d}$ \\
$a_{1, G R m}$ & Fourier coefficient for GR mRNA & $6.8^{a} / 162.2^{b} /-273.2^{c, d}$ \\
$a_{2, G R m}$ & Fourier coefficient for GR mRNA & $65.9^{c, d}$ \\
$b_{1, G R m}$ & Fourier coefficient for GR mRNA & $185.6^{a} /-19.9^{b} /-10.9^{c, d}$ \\
$b_{2, G R m}$ & Fourier coefficient for GR mRNA & $10.1^{c, d}$ \\
$k_{d, G R m}\left(\mathrm{~h}^{-1}\right)$ & Degradation rate constant for GR mRNA & $0.26(15.4)^{a} / 0.28^{b}(29.9) / 0.31^{c, d}$ \\
$k_{S, G R}(\mathrm{nM} / \mathrm{h})(\mathrm{mol} / \mathrm{ng})^{-1}$ & Synthesis rate constant for receptor & $0.00025(5.3)^{a} / 0.00121^{b}(34.5) / 0.00196^{c, d}$ \\
$I C_{50, G R m}\left(\mathrm{nM}^{-1}\right)$ & Inhibition of GR mRNA production & $15.6^{e}$ \\
$k_{d, G R}\left(\mathrm{~h}^{-1}\right)$ & Degradation rate constant for receptor & $0.05^{e}$ \\
$k_{\text {on }}\left(\mathrm{nM}^{-1} \cdot \mathrm{h}^{-1}\right)$ & Association rate constant & $0.016^{e}$ \\
$f_{m p l}$ & Unbound fraction of MPL in plasma & $0.23^{e}$ \\
$k_{r e}\left(\mathrm{~h}^{-1}\right)$ & DR loss rate constant & $1.31^{e}$ \\
$R_{f}$ & Fraction recycled & $0.93^{e}$ \\
$k_{T}\left(\mathrm{~h}^{-1}\right)$ & Translocation rate constant & $58.3^{e}$ \\
$G R_{m, M P L}(0)(\mathrm{mol} / \mathrm{ng} \mathrm{RNA})$ & GR mRNA initial concentration (treatment) & $4000(\text { fixed })^{a} / 1350^{b}(10.7) / 2200^{c, d}$ \\
$G R(0)(\mathrm{nM})$ & Free cytosolic receptor initial concentration & $19.7(5.3)^{a} / 32.7^{b}(34.5) / 86.2^{c, d}$ \\
$D R(0)(\mathrm{nM})$ & Drug-receptor complex initial concentration & 0 (fixed) \\
$D R_{n}(0)(\mathrm{nM})$ & Nuclear complex initial concentration & 0 (fixed) \\
\hline
\end{tabular}

${ }^{a}$ Lung.

${ }^{b}$ Muscle.

${ }^{c}$ Parameter values fixed from Sukumaran et al. (2011).

${ }^{d}$ Adipose tissue.

${ }^{e}$ Parameter values fixed from Hazra et al. (2007a).

estimated parameters for GILZ dynamics (eqs. 10-12) for all three tissues are provided in Table 3 .

Fig. 8 shows that GILZ mRNA is upregulated in muscle, but to a lesser extent compared with lung and adipose. GILZ expression is enhanced 0.5 hours after MPL dosing and sharply rises to its peak $(15,851 \pm 2598$ molecules/ng RNA $)$ by 5-6 hours, which was earlier than peak times of GILZ in adipose tissue and lung. Conversely, the peak time of basal mRNA expression in muscle was delayed compared with that in adipose tissue and lung (Fig. 7). In general, the model adequately captured the magnitude of up-regulation of GILZ by MPL as well as its return to circadian baseline, but it overestimated the time of peak response in muscle. This is likely due to the simultaneous fitting of the baseline profile along with the treatment dynamics, where an appreciable difference in times of peak expression was observed. The estimated $k_{d, G I L Z m}$ in muscle was $0.16 \mathrm{hour}^{-1}(14.3 \mathrm{CV} \%)$. The linear stimulatory constant of GILZ mRNA synthesis $\left(S_{D R}^{G I L Z m}\right)$ in muscle was estimated as $0.27 \mathrm{nM}^{-1}(40 \mathrm{CV} \%)$. GILZ mRNA expression was strongly upregulated upon dosing with MPL in adipose, showing a steady increase in expression starting as early as 30 minutes after MPL and reaching its maximum around 8 hours $(55,053 \pm 1342$ molecules/ng RNA), which was well described by the model. The estimated degradation constant of GILZ mRNA $\left(k_{d, G I L Z m}\right)$ in adipose tissue was 0.21 hour $^{-1}$ (5.8 CV\%), which corresponds to a turnover halflife of approximately 3.3 hours. The estimated $S_{D R_{n}}^{G I L Z m}$ value of $0.3 \mathrm{nM}^{-1}$ (8.3 CV\%) in adipose was very similar to that in muscle. Drug-induced GILZ expression exceeded the amplitude of its baseline rhythm in lung by 2 hours after dosing, and peaked around 8 hours $(41,952 \pm 1519$ molecules/ng RNA). The mRNA returned to baseline by 24 hours, after which circadian rhythmicity was re-established. The model well described the enhancement as well as the return to rhythmic baseline expression of GILZ upon acute MPL dosing. The estimated $k_{d, G I L Z m}$ value of $0.45 \mathrm{hour}^{-1}(7.7 \mathrm{CV} \%)$ indicated that the turnover half-life of GILZ mRNA is approximately 1.5 hours in lung, about twice as rapid compared with adipose tissue. The $S_{D R_{n}}^{G I L Z m}$ in lung was estimated to be $0.47 \mathrm{nM}^{-1}(6.8$ CV\%). Of interest, although the baseline oscillation of GILZ in lung was more robust than in adipose, the extent of MPLmediated enhancement of GILZ mRNA from baseline in lung was lower.

GILZ mRNA Dynamics upon Chronic MPL Dosing. The dynamic behavior of steroid-regulated genes can differ based upon the nature of the perturbation introduced within the system (Almon et al., 2007a). The time course of GILZ mRNA expression was assessed in lung and adipose following an infusion of $0.3 \mathrm{mg} / \mathrm{kg} / \mathrm{h}$ MPL over 7 days. The concentrationtime profile for the chronic infusion was simulated based on the parameters in Table 1. The developed pharmacodynamic model was simulated using parameter values obtained for receptor and GILZ dynamics from Tables 2 and 3 to predict GILZ mRNA dynamics in lung and adipose tissue measured from these animals. Chronically elevated steroid concentrations disrupt or even abrogate the circadian rhythmicity of endogenous CST and tissue gene expression (Cole et al., 2000; Chung et al., 2011), and the significantly greater exogenous steroid would contribute more to stimulating target mRNA expression (Hazra et al., 2007a). Thus, circadian rhythmicity for both GR and GILZ mRNA was not included for the chronic regimen, and steady baselines were assumed. Simulations using the model and its parameters satisfactorily predicted the data patterns for both tissues.

The infusion of MPL produced a robust increase in GILZ mRNA in adipose tissue (Fig. 9) with the peak expression reaching 59,720 $\pm 12,947$ molecules/ng RNA at around 8-9 hours. However, expression decreased from the peak to achieve a new steady-state despite the constant presence of drug, indicating a drug-induced tolerance phenomenon. The model captured the enhancement of GILZ mRNA upon chronic infusion and, more importantly, was able to accurately predict the steadystate dynamics achieved beyond 48 hours and throughout the 7-day infusion. A similar pattern of expression was observed in lung (Fig. 9), with GILZ mRNA being enhanced to peak between 6 and 9 hours after starting the infusion. Consistent with 


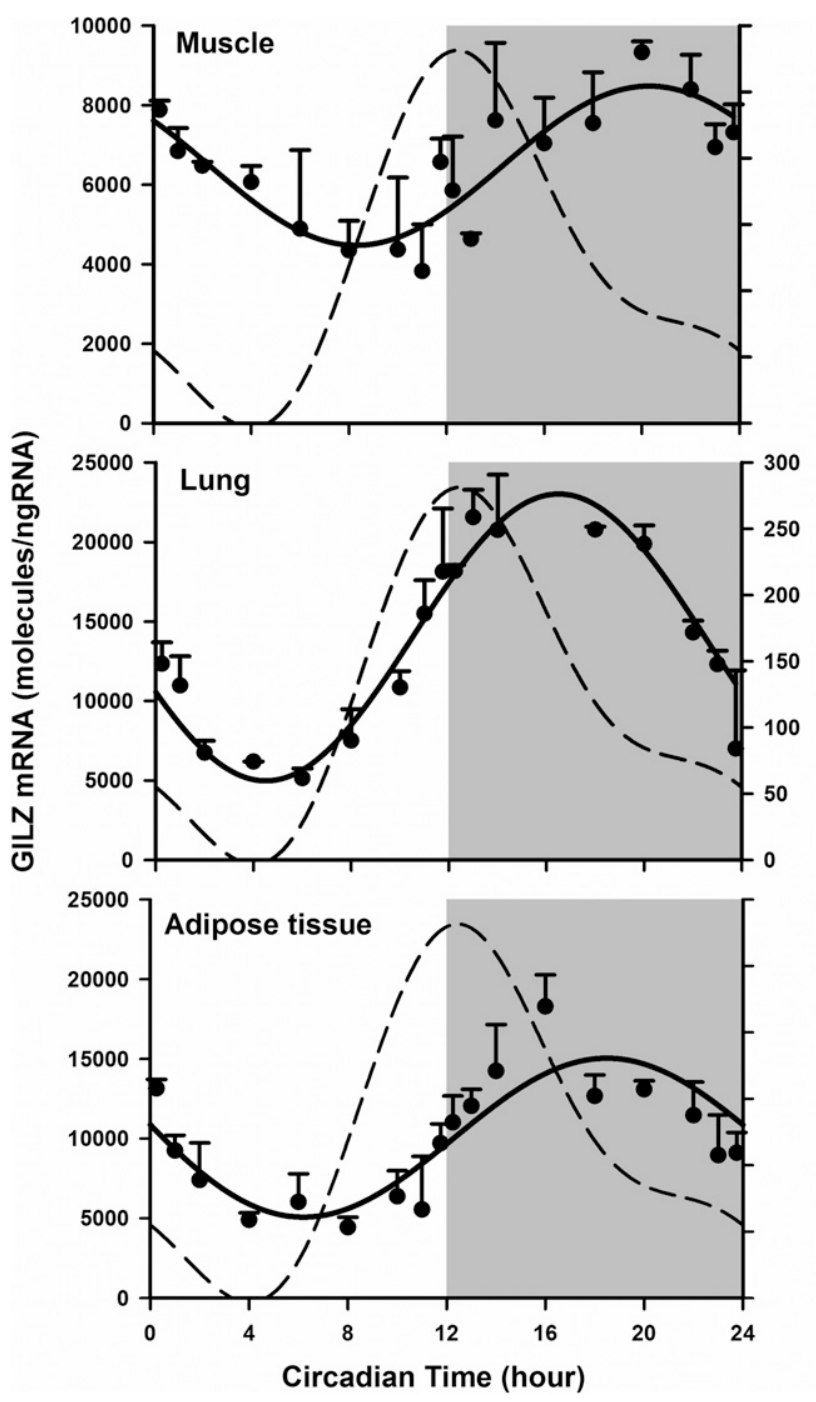

Fig. 7. Circadian rhythm of GILZ mRNA expression in three tissues from baseline-control animals. Circles represent the mean and error bars, 1 standard deviation $(n=3)$. The solid line depicts the fitting results using the PK/PD model depicted in Fig. 3. The dashed line represents plasma corticosterone measurements from the same animals.

measurements from the acute dosing study, enhancement by MPL in lung was appreciably lower compared with adipose tissue. Expression in lung peaked at 31,692 \pm 6050 molecules/ng RNA and decreased to a steady-state of approximately 23,000 molecules/ng RNA, which was well captured by the model.

Simulation of Receptor Dynamics upon Chronic MPL Dosing. Several hypotheses exist for explaining the changes in steroid-regulated tissue gene expression after acute versus chronic dosing. It is possible that molecular events (receptor translocation, recycling, or chromatin binding) are altered during chronic dosing. Alternatively, signal transduction processes involved in generating the response can be amplified or diminished due to the chronic presence of steroid. Furthermore, secondarily induced alterations in other hormones, such as insulin and glucagon, can influence the expression of responsive genes, such as TAT and PEPCK, upon chronic drug exposure (Holten and Kenney, 1967; Jin et al., 2004). To understand the molecular mechanisms governing the tolerance and tissue-specific GILZ dynamics observed with chronic dosing, we

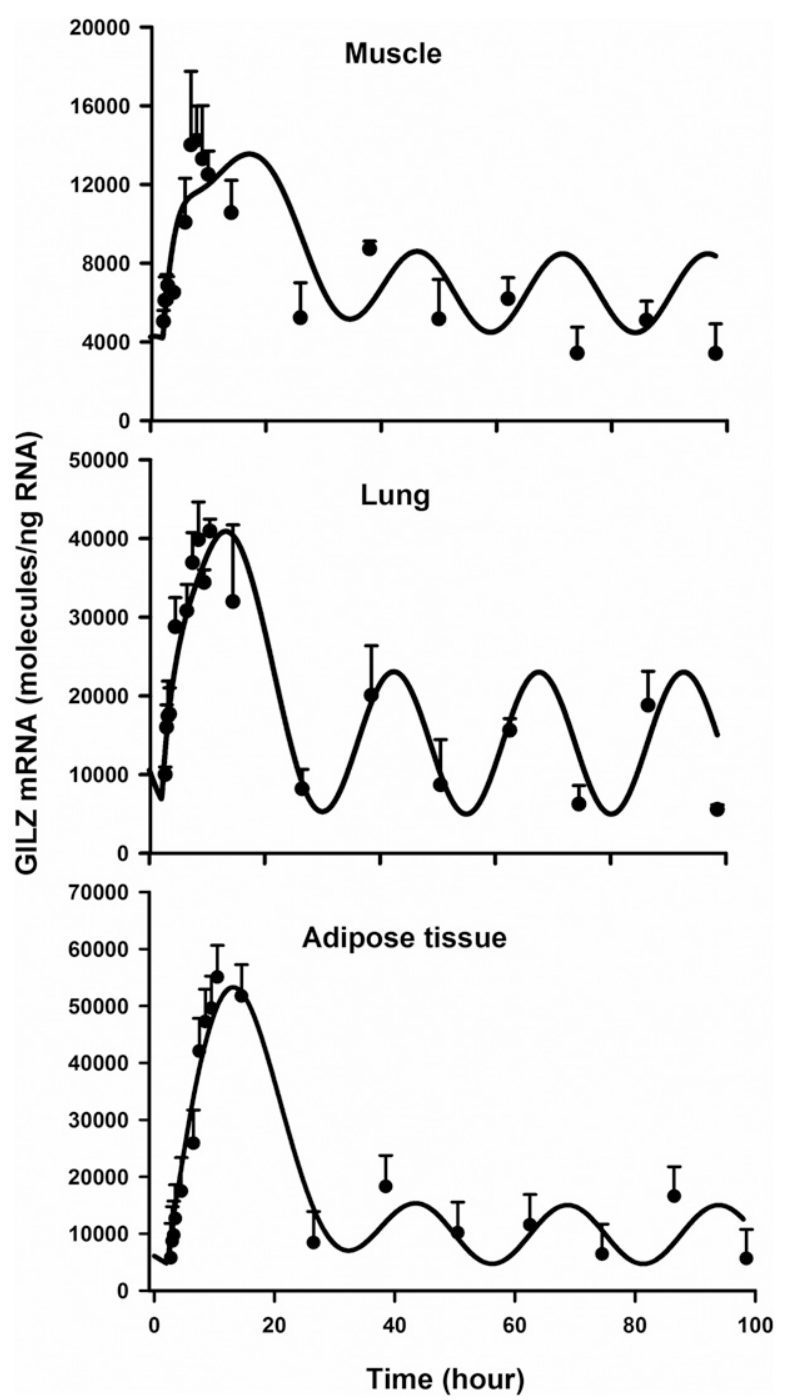

Fig. 8. GILZ mRNA expression in three tissues from rats given $50 \mathrm{mg} / \mathrm{kg}$ IM MPL. Circles represent the mean and error bars, 1 standard deviation $(n=3)$ The solid lines show model fittings (Fig. 3) using parameter estimates listed in Table 3.

performed simulations of the GR mRNA, free cytosolic receptor $(R)$, drug-receptor complex $(D R)$, and nuclear drug-receptor complex $\left(D R_{n}\right)$ in lung and adipose tissue (Fig. 10).

Whereas a rapid down-regulation of receptor mRNA was observed upon steroid exposure in both tissues, it took up to 24 hours for attainment of steady-state. The model predicted a 50\%-55\% decrease in GR mRNA expression from the controls in adipose tissue, which was similar to that observed in liver from chronically infused male ADX rats (Ramakrishnan et al., $2002 \mathrm{~b}$ ). The extent of down-regulation in lung was lower compared with adipose tissue, consistent with our observations in the acutely dosed animals. Cytosolic receptor density took as long as 48 hours before achieving steady-state concentrations in both tissues. The simulated profile of $D R$ concentrations in the cytosol showed a quick increase followed by a relatively rapid decrease to a lower steady state in both tissues. The concentrations of $D R_{n}$ present in the nucleus peaked at 3 hours into the infusion, which followed the increase and return of $D R$ complex to its own steady-state, with a slight time delay. The time courses of these simulated GR dynamic profiles are in 
TABLE 3

Parameter values for the dynamics of GILZ mRNA expression

\begin{tabular}{|c|c|c|}
\hline Parameter & Definition & Estimate (CV\%) \\
\hline $\begin{array}{l}a_{0, G I L Z m} \\
a_{1, G I L Z m} \\
b_{1, G I L Z m} \\
k_{d, G I L Z m}\left(\mathrm{~h}^{-1}\right)\end{array}$ & $\begin{array}{l}\text { Fourier coefficient for GILZ mRNA } \\
\text { Fourier coefficient for GILZ mRNA } \\
\text { Fourier coefficient for GILZ mRNA } \\
\text { Degradation rate constant for GILZ mRNA }\end{array}$ & $\begin{array}{c}14,002^{a} / 6479^{b} / 9845^{c} \\
-3447^{a} / 1133^{b} /-441^{c} \\
-8339^{a} /-1651^{b} /-5148^{c} \\
0.45^{a}(7.7) / 0.16^{b}(14.3) / 0.21^{c}(5.8)\end{array}$ \\
\hline $\begin{array}{l}S_{D R n}{ }^{G I L Z m}\left(\mathrm{nM}^{-1}\right) \\
G I L Z_{m M P L}(0)(\mathrm{mol} / \mathrm{ng} \mathrm{RNA})\end{array}$ & $\begin{array}{l}\text { Stimulation of GILZ mRNA production } \\
\text { GILZ mRNA initial concentration (treatment) }\end{array}$ & $\begin{array}{c}0.47^{a}(6.8) / 0.27^{b}(40.0) / 0.3^{c}(8.3) \\
10,560^{a} \text { (fixed)/4249 }(17.9) / 6077^{c}(21.3)\end{array}$ \\
\hline
\end{tabular}

general agreement with previous chronic infusion studies assessing liver dynamics of ADX animals (Ramakrishnan et al., 2002a). The concentration of $D R_{n}$ formation in adipose tissue was about 3 - to 4 -fold higher than $D R_{n}$ in lung, which might conceivably explain the increased capacity for GILZ gene enhancement in adipose tissue versus lung.

\section{Discussion}

Despite increasing clinical use of targeted biologics for immune-related diseases, CS remain a cornerstone in therapy owing to their widespread immunosuppressive effects. Among a few other transactivated genes, GILZ has been implicated in mediating anti-inflammatory CS effects (Ayroldi and Riccardi, 2009; Vandevyver et al., 2013). In this report, we sought to establish a mechanistic and quantitative basis using PK/PD modeling for the tissue-specific enhancement of GILZ by MPL under different dosing regimens in vivo.

CS exert therapeutic and adverse effects in various organs via a coupled receptor-mediated mechanism. The catabolic effects of MPL dosing on organ weights display different sensitivities or capacities to respond to steroid treatment, which are dependent upon drug-receptor association and receptor densities within the tissues (Ramakrishnan et al., 2002b). Less is known regarding the precise mechanisms controlling differences in expression of a single or multiple genes across tissues. Here, we examined whether such tissue-specific regulation of GR controls differences at the level of gene expression across tissues.

Endogenous glucocorticoid production from the adrenal cortex is regulated in a circadian fashion by the hypothalamicpituitary-adrenal axis via input from the suprachiasmatic nucleus, consequently producing oscillations in steroidregulated genes in tissues. Such time-dependent variations in gene expression influence drug action, including pharmacodynamic responses, due to the availability or functioning of target proteins (Sukumaran et al., 2010). Hence, conclusions made from time-course studies require consideration of such oscillatory behaviors. All measures of GR and GILZ mRNA expression examined in our study displayed circadian oscillations. We examined the circadian regulation of GR $\mathrm{mRNA}$ and its dynamics after acute MPL dosing in skeletal muscle, lung, and adipose tissue. Although it was not surprising to find that the amount of receptor mRNA expression varied across tissues, it was interesting to identify distinct, tissue-specific patterns of circadian rhythmicity, which can be of physiologic importance. For example, the nadir of GR rhythmicity in skeletal muscle occurred at the transition from light to dark, which coincides with the time of peak plasma CST concentration. This pattern is in direct contrast to adipose tissue, where GR mRNA peaked at the light-to-dark transition period. Such divergent tissue behavior may be explained from the standpoint of energy metabolism (Laposky et al., 2008). Since the animal is not feeding during the light/inactive period, it is dependent upon free fatty acid release from lipolysis as its main energy source, explaining a timely increase in GR expression to facilitate this process in adipose. Conversely, since glucocorticoids promote net protein degradation in muscle (Vegiopoulos and Herzig, 2007), decreased GR expression might serve as a protective mechanism against this effect. The circadian pattern of GR in lung was entrained to
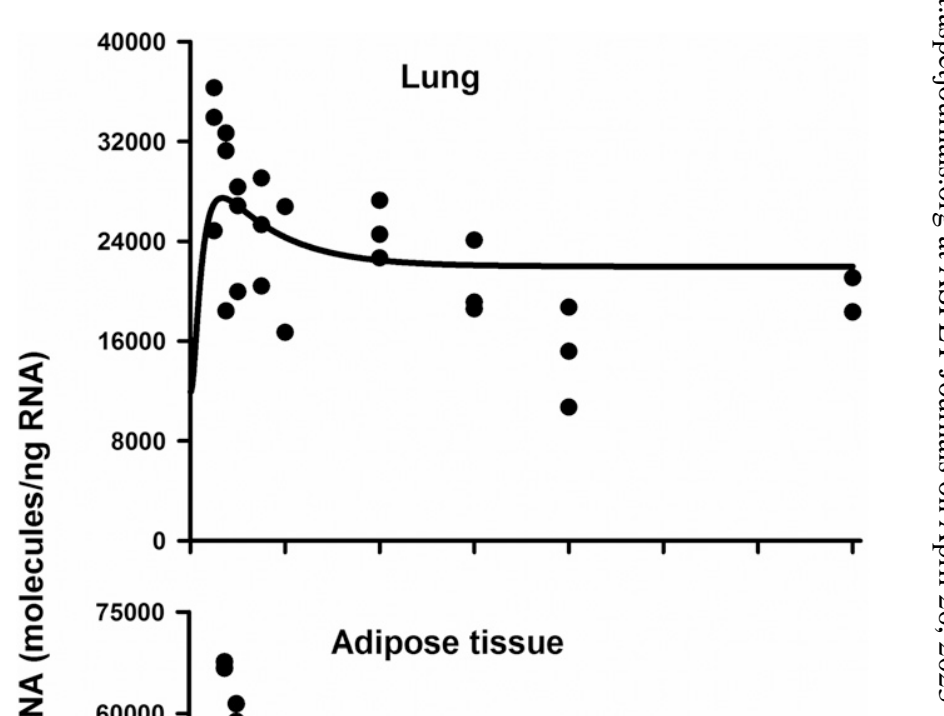

Fig. 9. GILZ mRNA expression in lung and adipose tissue from rats infused with $0.3 \mathrm{mg} / \mathrm{kg} / \mathrm{h}$ SC MPL for 7 days. Solid circles represent experimental data from individual rats, and solid lines are simulations using the PK/PD model depicted in Fig. 3. The parameters used are those for acute steroid effects listed in Table 3 . 


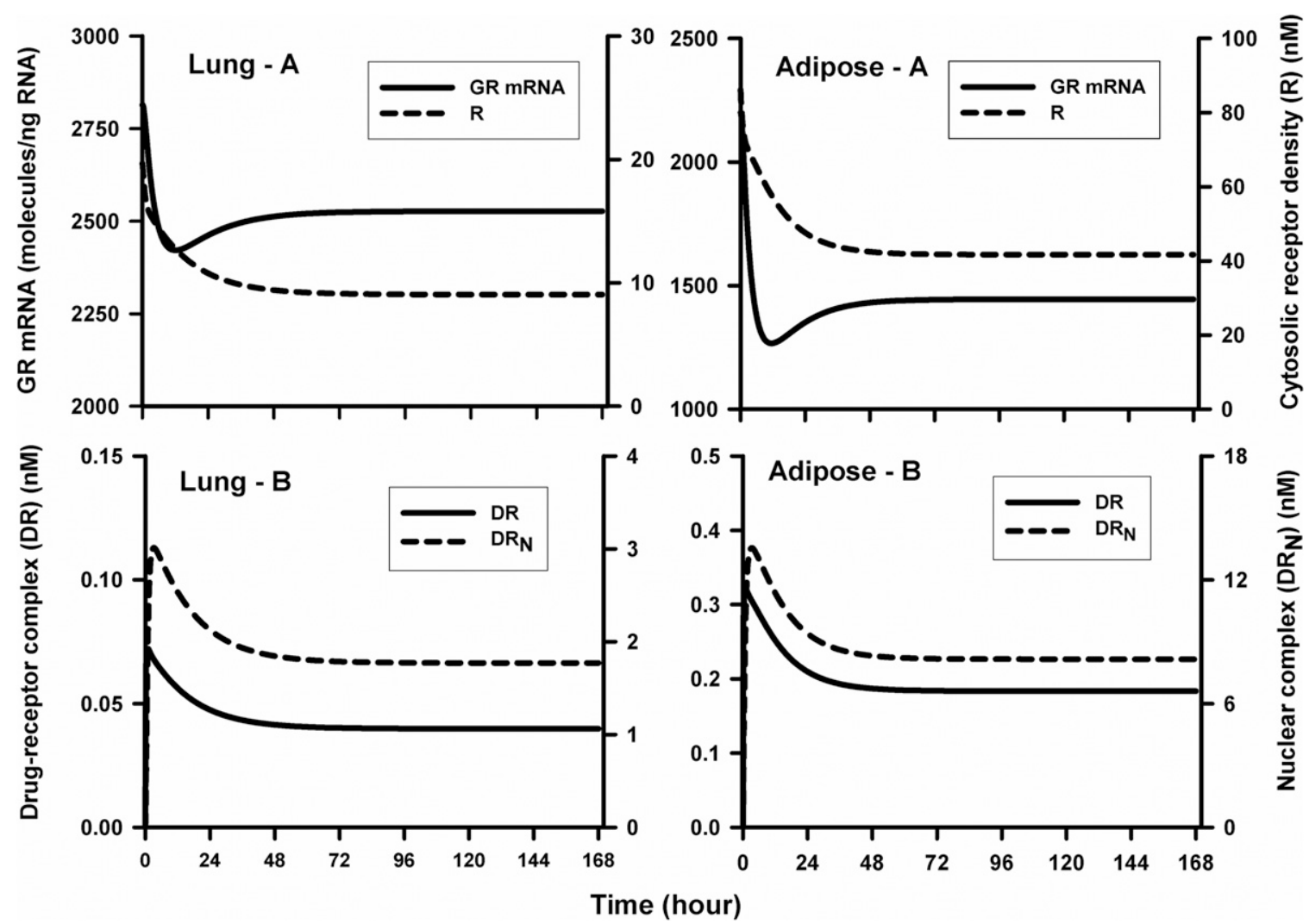

Fig. 10. Simulated profiles of the driving forces (GR mRNA, free cytosolic receptor, and drug-receptor complex in the cytosol and nucleus) controlling GILZ regulation in lung and adipose tissue from rats infused with $0.3 \mathrm{mg} / \mathrm{kg} / \mathrm{h}$ MPL for 7 days. Simulations are based on the model in Fig. 3. The parameters are those for acute MPL effects as listed in Tables 2 and 3.

adrenal CST production, but the direct physiologic relevance of this behavior is not apparent. The MPL bolus dosing led to a rapid decrease in receptor mRNA in all three tissues, consistent with previous findings of tissue-specific GR mRNA regulation by dexamethasone (Kalinyak et al., 1987). The tissue dynamics followed relatively similar patterns over time, likely due to similar degradation-rate constants.

The GILZ mRNA regulation in all three tissues followed a pattern that is entrained to the CST rhythm. CST, however, only partially controls the cyclic GILZ expression, since adrenalectomy does not completely abolish the circadian rhythm of GILZ mRNA in tissues (Sotak et al., 2016). Our results provide in vivo confirmation of prior in vitro studies (D'Adamio et al., 1997; Smit et al., 2005; Aguilar et al., 2013), showing that GILZ transcription is strongly enhanced upon CS exposure. The half-life of GILZ mRNA expression was estimated to be around 3-4 hours in muscle $\left(k_{d, G I L Z m}=0.16\right.$ hour $\left.^{-1}\right)$ and adipose tissue $\left(k_{d, \text { GILZm }}=\right.$ 0.21 hour $\left.^{-1}\right)$ and 1.5 hours in lung $\left(k_{d, \text { GILZm }}=0.45\right.$ hour $\left.^{-1}\right)$. Differences in mRNA degradation rate could arise from cell- or tissue-specific differences in cytoplasmic mRNA decay mechanisms (Linde et al., 2007; Schoenberg and Maquat, 2012). The concerted regulation of circadian rhythmicity and CS pharmacodynamics was apparent in lung and adipose tissue based upon simultaneous model fitting of the circadian and acute dosing profiles. The dynamics of GILZ in muscle, however, showed some divergence in the circadian and treatment profiles, which led to a discrepancy between the observed and model-estimated times of peak response in the treatment group. This could be caused by the direct tissue-specific effects of CS, which produce an apparent phase shift in peripheral-clock response in intact animals (Balsalobre et al., 2000), which was not accounted for in this model. While we speculate that the higher sensitivity constant $\left(S_{D R_{n}}^{G I L Z m}\right)$ in lung (beyond receptor differences) may arise due to the distinct primary roles of CS in lung versus muscle and adipose (i.e., immune versus metabolic regulation), our findings based on in vivo measurements may provide some basis for further experimental assessments of this molecular process in vitro.

Chronic MPL produced a different dynamic behavior of GILZ expression compared with acute dosing. Prior microarray studies in muscle and liver following chronic MPL infusion indicated that various temporal patterns emerge for the drugregulated genes (Almon et al., 2007a,b). GILZ dynamics in both lung and adipose tissue showed a recognizable pattern where expression was rapidly enhanced to a peak, but then decreased over 24 hours to achieve a new steady-state that was maintained until the end of the 7-day study period.

Quantitative systems modeling was used to understand the dynamic mechanisms controlling tissue-specific MPL effects. Assuming the kinetics of drug entry into the tissues studied are not rate-limiting (i.e., well perfused tissue entry), the dissociation constant for the drug-receptor binding and the free receptor density (as controlled by de novo receptor synthesis and degradation, the recycled fraction, and receptor mRNA autoregulation) would limit the overall response of tissues to steroid treatment. We therefore measured the dynamics of GR message expression in the selected tissues and simulated tissue-specific free receptor densities using our 
model. The short half-life of MPL ( $\sim 30$ minutes) resulted in steady-state concentrations being achieved within a few hours during chronic infusion. However, simulation of lung and adipose tissue receptor dynamics showed that it takes at least 24 hours for the steady-state to be attained, consistent with the time course of receptor measures in ADX liver (Ramakrishnan et al., 2002b). The fifth-generation model captured GILZ dynamics in both tissues while demonstrating that receptor down-regulation was the common mechanism controlling the tolerance in pharmacogenomic responses. Also demonstrated was that tissue-specific concentrations of the steroid-receptor complex $\left(D R_{n}\right)$ corresponded with the capacity of MPL-mediated GILZ enhancement in those tissues. Interestingly, the same model indicated that postreceptor events contributed to a decoupling between receptor dynamics and hepatic TAT gene induction during long-term dosing, attributed to secondarily induced changes in insulin, which also regulates TAT (Ramakrishnan et al., 2002b). Our model simulations suggest that certain parameters such as $k_{o n}, k_{r e}, k_{t}$, and $R_{f}$, fixed to constant values across the tissues based on bolus dose estimates, are less likely to influence the divergence in the tissue- and dosage regimen-dependent behaviors of GILZ in vivo.

A salient feature of this study is that replicate data obtained from both circadian and MPL experiments were modeled jointly to obtain parameter values. Despite the model being developed based on a single dose and using a linear stimulation coefficient $\left(S_{D R_{n}}^{G I L Z m}\right)$ instead of a more appropriate saturable effect function, the final model well predicted GILZ dynamics upon chronic steroid exposure. A limitation is the assumption of a normal CST rhythm in acutely dosed animals. In reality, MPL causes suppression of endogenous CST by binding to GR in the pituitary, thereby modulating its release from the adrenal cortex (Cole et al., 2000; Yao et al., 2008). This, in turn, could modulate endogenous GILZ expression. However, MPL binds GR with higher affinity than CST, predominantly exerting receptor/gene-mediated effects when present in the system. Furthermore, adrenalectomy dampens the amplitude but does not abolish circadian GILZ expression in tissues (Sotak et al., 2016), possibly indicating an added regulatory mechanism involving peripheral clock genes. Since inclusion of these processes without additional data would have resulted in overparameterization, a semimechanistic IDR approach based on Fourier harmonics was used to describe the nonstationarity in baselines.

These studies quantitatively assess CS kinetics, dynamics, and genomics on the molecular and tissue levels while accounting for circadian rhythms, providing a physiologically integrated examination of how multiple factors interact to control the in vivo responses to an important class of therapeutic agents. These studies lay the foundation to investigate sex differences in the PK/PD response to CS using GILZ as a biomarker (Whirledge and Cidlowski, 2013). Also of importance would be to examine the regulation of GILZ in animal models of inflammatory disease (Earp et al., 2009), since GILZ is an anti-inflammatory mediator in rheumatoid arthritis (Beaulieu et al., 2010). Enhanced pharmacodynamic models are being applied to provide a deeper understanding of drug action from molecular to whole-system responses (Iyengar et al., 2012; Jusko, 2013). The present findings of tissue-specific differences in basal and drug-induced expressions and their controlling mechanisms indicate that such factors should be considered in view of the dose, pharmacokinetics, pharmacodynamics, and target organ actions for drugs acting through genomic mechanisms.

\section{Authorship Contributions}

Participated in research design: Ayyar, DuBois, Almon, Jusko.

Conducted experiments: Ayyar, DuBois.

Performed data analysis: Ayyar, Jusko.

Wrote or contributed to the writing of the manuscript: Ayyar, DuBois, Almon, Jusko.

\section{References}

Aguilar DC, Strom J, Xu B, Kappeler K, and Chen QM (2013) Expression of glucocorticoid-induced leucine zipper (GILZ) in cardiomyocytes. Cardiovasc Toxicol 13:91-99.

Almon RR, Dubois DC, Jin JY, and Jusko WJ (2005a) Pharmacogenomic responses of rat liver to methylprednisolone: an approach to mining a rich microarray time series. AAPS J 7:E156-E194.

Almon RR, DuBois DC, and Jusko WJ (2007a) A microarray analysis of the temporal response of liver to methylprednisolone: a comparative analysis of two dosing regimens. Endocrinology 148:2209-2225.

Almon RR, DuBois DC, Yao Z, Hoffman EP, Ghimbovschi S, and Jusko WJ (2007b) Microarray analysis of the temporal response of skeletal muscle to methylprednisolone: comparative analysis of two dosing regimens. Physiol Genomics 30:282-299.

Almon RR, Lai W, DuBois DC, and Jusko WJ (2005b) Corticosteroid-regulated genes in rat kidney: mining time series array data. Am J Physiol Endocrinol Metab 289 : E870-E882.

Almon RR, Yang E, Lai W, Androulakis IP, DuBois DC, and Jusko WJ (2008) Circadian variations in rat liver gene expression: relationships to drug actions. $J$ Pharmacol Exp Ther 326:700-716.

Ayroldi E, Petrillo MG, Bastianelli A, Marchetti MC, Ronchetti S, Nocentini G, Ricciotti L, Cannarile L, and Riccardi C (2015) L-GILZ binds p53 and MDM2 and suppresses tumor growth through p53 activation in human cancer cells. Cell Death Differ 22:118-130.

Ayroldi E and Riccardi C (2009) Glucocorticoid-induced leucine zipper (GILZ): a new important mediator of glucocorticoid action. FASEB J 23:3649-3658.

Ayyar VS, Almon RR, Jusko WJ, and DuBois DC (2015) Quantitative tissue-specific dynamics of in vivo GILZ mRNA expression and regulation by endogenous and exogenous glucocorticoids. Physiol Rep 3:e12382.

Balsalobre A, Brown SA, Marcacci L, Tronche F, Kellendonk C, Reichardt HM Schütz G, and Schibler U (2000) Resetting of circadian time in peripheral tissues by glucocorticoid signaling. Science 289:2344-2347.

Barnes PJ (1998) Efficacy of inhaled corticosteroids in asthma. J Allergy Clin Immunol 102:531-538.

Barnes PJ (2006) How corticosteroids control inflammation: Quintiles Prize Lecture 2005. Br J Pharmacol 148:245-254.

Beaulieu E, Ngo D, Santos L, Yang YH, Smith M, Jorgensen C, Escriou V, Scherman D, Courties G, Apparailly F, et al. (2010) Glucocorticoid-induced leucine zipper is an endogenous antiinflammatory mediator in arthritis. Arthritis Rheum 62: 2651-2661.

Bruscoli S, Biagioli M, Sorcini D, Frammartino T, Cimino M, Sportoletti P, Mazzon E, Bereshchenko O, and Riccardi C (2015) Lack of glucocorticoid-induced leucine zipper (GILZ) deregulates B-cell survival and results in B-cell lymphocytosis in mice. Blood 126:1790-1801.

Bustin SA, Benes V, Garson JA, Hellemans J, Huggett J, Kubista M, Mueller R, Nolan T, Pfaffl MW, Shipley GL, et al. (2009) The MIQE guidelines: minimum information for publication of quantitative real-time PCR experiments. Clin Chem 55:611-622.

Cannarile L, Zollo O, D'Adamio F, Ayroldi E, Marchetti C, Tabilio A, Bruscoli S, and Riccardi C (2001) Cloning chromosomal assignment and tissue distribution of human GILZ, a glucocorticoid hormone-induced gene. Cell Death Differ 8:201-203.

Chung S, Son GH, and Kim K (2011) Circadian rhythm of adrenal glucocorticoid: Its regulation and clinical implications. Biochim Biophys Acta 1812:581-591.

Cole MA, Kim PJ, Kalman BA, and Spencer RL (2000) Dexamethasone suppression of corticosteroid secretion: evaluation of the site of action by receptor measures and functional studies. Psychoneuroendocrinology 25:151-167.

D’Adamio F, Zollo O, Moraca R, Ayroldi E, Bruscoli S, Bartoli A, Cannarile L, Migliorati G, and Riccardi C (1997) A new dexamethasone-induced gene of the leucine zipper family protects T lymphocytes from TCR/CD3-activated cell death. Immunity 7:803-812.

D'Argenio D, Schumitzky A, and Wang X(2009) ADAPT 5 User's Guide: Pharmacokinetic/Pharmacodynamic Systems Analysis Software BioMedical Simulations Resource, Los Angeles.

Di Marco B, Massetti M, Bruscoli S, Macchiarulo A, Di Virgilio R, Velardi E, Donato V, Migliorati G, and Riccardi C (2007) Glucocorticoid-induced leucine zipper (GILZ)/NF-kappaB interaction: role of GILZ homo-dimerization and C-terminal domain. Nucleic Acids Res 35:517-528.

DuBois DC, Xu ZX, McKay L, Almon RR, Pyszcznski N, and Jusko WJ (1995) Differential dynamics of receptor down-regulation and tyrosine aminotransferase induction following glucocorticoid treatment. J Steroid Biochem Mol Biol 54:237-243.

Earp JC, Dubois DC, Almon RR, and Jusko WJ (2009) Quantitative dynamic models of arthritis progression in the rat. Pharm Res 26:196-203.

Eddleston J, Herschbach J, Wagelie-Steffen AL, Christiansen SC, and Zuraw BL (2007) The anti-inflammatory effect of glucocorticoids is mediated by glucocorticoidinduced leucine zipper in epithelial cells. J Allergy Clin Immunol 119:115-122.

Haughey DB and Jusko WJ (1988) Analysis of methylprednisolone, methylprednisone and corticosterone for assessment of methylprednisolone disposition in the rat. J Chromatogr A 430:241-248. 
Haughey DB and Jusko WJ (1992) Bioavailability and nonlinear disposition of methylprednisolone and methylprednisone in the rat. J Pharm Sci 81:117-121.

Hazra A, Pyszczynski N, DuBois DC, Almon RR, and Jusko WJ (2007a) Modeling receptor/gene-mediated effects of corticosteroids on hepatic tyrosine aminotransferase dynamics in rats: dual regulation by endogenous and exogenous corticosteroids. J Pharmacokinet Pharmacodyn 34:643-667.

Hazra A, Pyszczynski N, DuBois DC, Almon RR, and Jusko WJ (2007b) Pharmacokinetics of methylprednisolone after intravenous and intramuscular administration in rats. Biopharm Drug Dispos 28:263-273.

Hazra A, Pyszczynski NA, DuBois DC, Almon RR, and Jusko WJ (2008) Modeling of corticosteroid effects on hepatic low-density lipoprotein receptors and plasma lipid dynamics in rats. Pharm Res 25:769-780.

Holten D and Kenney FT (1967) Regulation of tyrosine alpha-ketoglutarate transaminase in rat liver. VI. Induction by pancreatic hormones. J Biol Chem 242:4372-4377.

Iyengar R, Zhao S, Chung S-W, Mager DE, and Gallo JM (2012) Merging systems biology with pharmacodynamics. Sci Transl Med 4:126ps7.

Jin JY, DuBois DC, Almon RR, and Jusko WJ (2004) Receptor/gene-mediated pharmacodynamic effects of methylprednisolone on phosphoenolpyruvate carboxykinase regulation in rat liver. J Pharmacol Exp Ther 309:328-339.

Jusko WJ (1995) Pharmacokinetics and receptor-mediated pharmacodynamics of corticosteroids. Toxicology 102:189-196.

Jusko WJ (2013) Moving from basic toward systems pharmacodynamic models. $J$ Pharm Sci 102:2930-2940.

Kalinyak JE, Dorin RI, Hoffman AR, and Perlman AJ (1987) Tissue-specific regulation of glucocorticoid receptor mRNA by dexamethasone. J Biol Chem $\mathbf{2 6 2}$ 10441-10444.

Kirwan JR; The Arthritis and Rheumatism Council Low-Dose Glucocorticoid Study Group (1995) The effect of glucocorticoids on joint destruction in rheumatoid arthritis. N Engl J Med 333:142-146.

Kofman S, Perlia CP, Boesen E, Eisenstein R, and Taylor, 3rd SG (1962) The role of corticosteroids in the treatment of malignant lymphomas. Cancer 15:338-345.

Kong AN and Jusko WJ (1991) Disposition of methylprednisolone and its sodium succinate prodrug in vivo and in perfused liver of rats: nonlinear and sequential first-pass elimination. J Pharm Sci 80:409-415.

Krzyzanski W, Chakraborty A, and Jusko WJ (2000) Algorithm for application of Fourier analysis for biorhythmic baselines of pharmacodynamic indirect response models. Chronobiol Int 17:77-93.

Laposky AD, Bass J, Kohsaka A, and Turek FW (2008) Sleep and circadian rhythms: key components in the regulation of energy metabolism. FEBS Lett 582:142-151.

Linde L, Boelz S, Neu-Yilik G, Kulozik AE, and Kerem B (2007) The efficiency of nonsense-mediated mRNA decay is an inherent character and varies among different cells. Eur J Hum Genet 15:1156-1162.

Newton R (2000) Molecular mechanisms of glucocorticoid action: what is important? Thorax 55:603-613.

Oakley RH and Cidlowski JA (1993) Homologous down regulation of the glucocorticoid receptor: the molecular machinery. Crit Rev Eukaryot Gene Expr 3:63-88.

Pratt WB and Toft DO (1997) Steroid receptor interactions with heat shock protein and immunophilin chaperones. Endocr Rev 18:306-360.

Ramakrishnan R, DuBois DC, Almon RR, Pyszczynski NA, and Jusko WJ (2002a) Fifthgeneration model for corticosteroid pharmacodynamics: application to steady-state receptor down-regulation and enzyme induction patterns during seven-day continuous infusion of methylprednisolone in rats. J Pharmacokinet Pharmacodyn 29:1-24.
Ramakrishnan R, DuBois DC, Almon RR, Pyszczynski NA, and Jusko WJ (2002b) Pharmacodynamics and pharmacogenomics of methylprednisolone during 7-day infusions in rats. J Pharmacol Exp Ther 300:245-256.

Schoenberg DR and Maquat LE (2012) Regulation of cytoplasmic mRNA decay. Nat Rev Genet 13:246-259.

Smit P, Russcher H, de Jong FH, Brinkmann AO, Lamberts SW, and Koper JW (2005) Differential regulation of synthetic glucocorticoids on gene expression levels of glucocorticoid-induced leucine zipper and interleukin-2. J Clin Endocrinol Metab 90:2994-3000.

Soták M, Bryndová J, Ergang P, Vagnerová K, Kvapilová P, Vodička M, Pácha J, and Sumová A (2016) Peripheral circadian clocks are diversely affected by adrenalectomy. Chronobiol Int 33:520-529.

Sukumaran S, Almon RR, DuBois DC, and Jusko WJ (2010) Circadian rhythms in gene expression: Relationship to physiology, disease, drug disposition and drug action. Adv Drug Deliv Rev 62:904-917.

Sukumaran S, Jusko WJ, DuBois DC, and Almon RR (2011) Mechanistic modeling of the effects of glucocorticoids and circadian rhythms on adipokine expression. $J$ Pharmacol Exp Ther 337:734-746.

Sun YN, DuBois DC, Almon RR, Pyszczynski NA, and Jusko WJ (1998) Dosedependence and repeated-dose studies for receptor/gene-mediated pharmacodynamics of methylprednisolone on glucocorticoid receptor down-regulation and tyrosine aminotransferase induction in rat liver. J Pharmacokinet Biopharm 26: 619-648.

Sun YN, McKay LI, DuBois DC, Jusko WJ, and Almon RR (1999) Pharmacokinetic/ Pharmacodynamic models for corticosteroid receptor down-regulation and glutamine synthetase induction in rat skeletal muscle by a Receptor/Gene-mediated mechanism. J Pharmacol Exp Ther 288:720-728.

Van Cantfort J and Gielen JE (1979) Comparison of rat and mouse circadian rhythm of cholesterol-7 alpha-hydroxylase activity. J Steroid Biochem 10:647-651.

van der Laan S, Sarabdjitsingh RA, Van Batenburg MF, Lachize SB, Li H, Dijkmans TF, Vreugdenhil E, de Kloet ER, and Meijer OC (2008) Chromatin immunoprecipitation scanning identifies glucocorticoid receptor binding regions in the proximal promoter of a ubiquitously expressed glucocorticoid target gene in brain. $J$ Neurochem 106:2515-2523.

Vandevyver S, Dejager L, Tuckermann J, and Libert C (2013) New insights into the antiinflammatory mechanisms of glucocorticoids: an emerging role for glucocorticoidreceptor-mediated transactivation. Endocrinology 154:993-1007.

Vegiopoulos A and Herzig S (2007) Glucocorticoids, metabolism and metabolic diseases. Mol Cell Endocrinol 275:43-61.

Whirledge S and Cidlowski JA (2013) Estradiol antagonism of glucocorticoid-induced GILZ expression in human uterine epithelial cells and murine uterus. Endocrinology 154:499-510.

Yao Z, DuBois DC, Almon RR, and Jusko WJ (2008) Pharmacokinetic/pharmacodynamic modeling of corticosterone suppression and lymphocytopenia by methylprednisolone in rats. J Pharm Sci 97:2820-2832.

Address correspondence to: Dr. William J. Jusko, Department of Pharmaceutical Sciences, School of Pharmacy and Pharmaceutical Sciences, State University of New York at Buffalo, Buffalo, NY, 14214. E-mail: wjjusko@ buffalo.edu 